\title{
NGNP Research and Development Status
}

\section{August 2010}
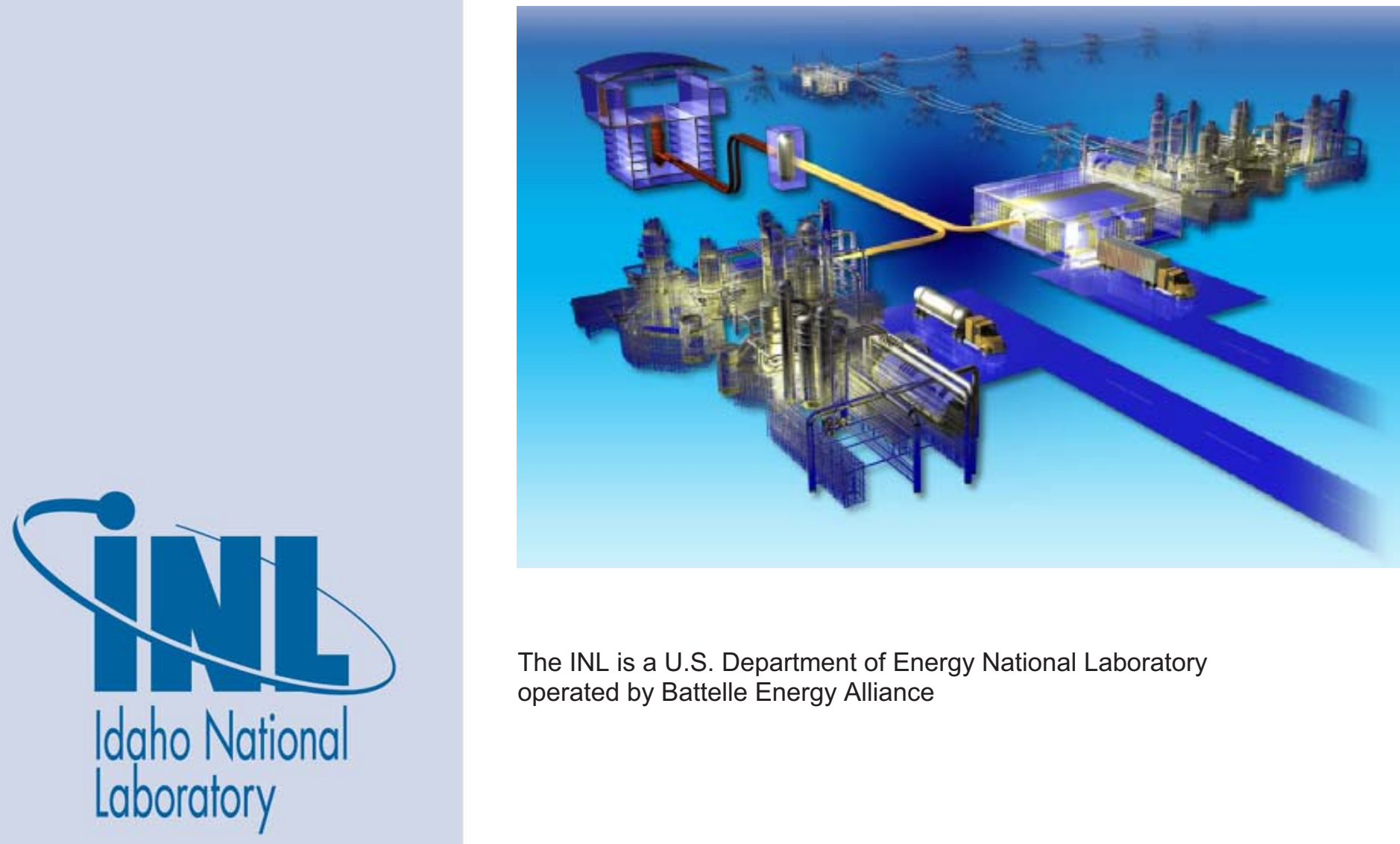

The INL is a U.S. Department of Energy National Laboratory operated by Battelle Energy Alliance 


\section{DISCLAIMER}

This information was prepared as an account of work sponsored by an agency of the U.S. Government. Neither the U.S. Government nor any agency thereof, nor any of their employees, makes any warranty, expressed or implied, or assumes any legal liability or responsibility for the accuracy, completeness, or usefulness, of any information, apparatus, product, or process disclosed, or represents that its use would not infringe privately owned rights. References herein to any specific commercial product, process, or service by trade name, trade mark, manufacturer, or otherwise, does not necessarily constitute or imply its endorsement, recommendation, or favoring by the U.S. Government or any agency thereof. The views and opinions of authors expressed herein do not necessarily state or reflect those of the U.S. Government or any agency thereof. 
INL/EXT-10-19259

\section{NGNP Research and Development Status}

August 2010

\section{Idaho National Laboratory Next Generation Nuclear Plant Project Idaho Falls, Idaho $\mathbf{8 3 4 1 5}$}

Prepared for the

U.S. Department of Energy

Office of Nuclear Energy

Under DOE Idaho Operations Office

Contract DE-AC07-05ID14517 

Next Generation Nuclear Plant Project

\section{Research and Development Status}

INL/EXT-10-19259

August 2010

Approved by:

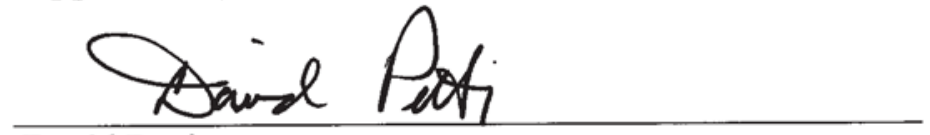

David Petti

Director, VHTR TDO

$8-11-10$

Date 


\section{SUMMARY}

Experts from the Department of Energy (DOE) national laboratories, gas reactor vendors, and universities collaborated to establish technology research and development (R\&D) roadmaps at the inception of the Next Generation Nuclear Plant (NGNP) project. These roadmaps outlined the testing and computational development activities needed to qualify the materials and validate the modeling and simulation tools to be used in the design and safe operation of the NGNP, a helium-cooled, high temperature gas reactor (HTGR). The technology development roadmaps draw on worldwide experience gained from the six demonstration and/or prototype HTGRs that have been built and operated over the past 60 years and their related technology development programs. The roadmaps include detailed descriptions of the required technical activities with associated schedules and budgets for completion of the activities and form the baseline for execution of the R\&D needed for the NGNP Project. The Technology R\&D activities are organized into six major technical areas:

- Fuel Development and Qualification,

- Graphite Development and Qualification,

- High temperature Materials Qualification,

- Design and Safety Methods Development and Validation,

- Heat Transport and System Integration, and

- Hydrogen Production.

Each area's objectives, current status, accomplishments to date, and future plans are discussed in this report. To accomplish these objectives, the Technology R\&D program draws upon expertise at DOE national laboratories, industry, and a broad array of universities along with international facilities and expertise accessible to the DOE via the Generation IV International Forum. A summary of international activities support NGNP R\&D is also provided. 


\section{CONTENTS}

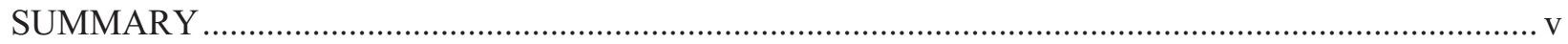

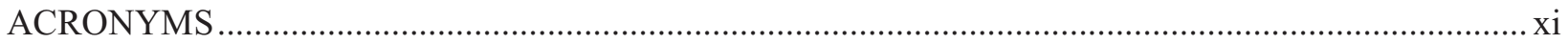

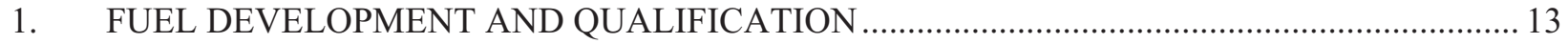

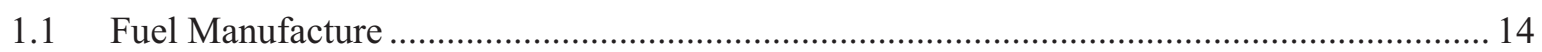

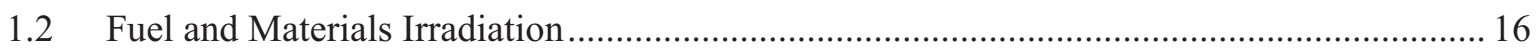

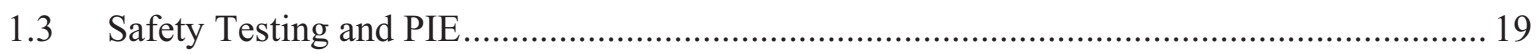

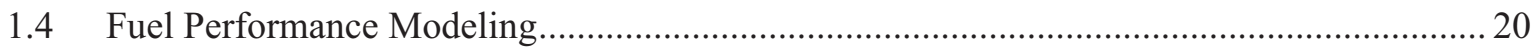

1.5 Fission Product Transport and Source Term................................................................. 21

1.6 Fuel Acquisition and Qualification Strategy................................................................... 21

1.7 Fuel Development and Qualification Program Schedule ................................................ 21

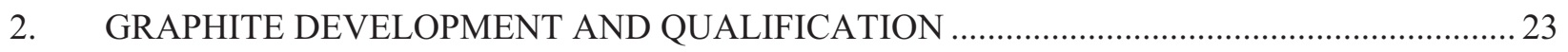

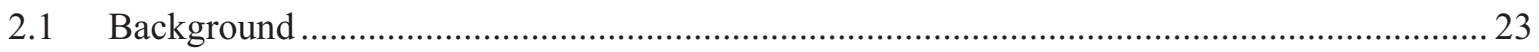

2.2 Graphite Development and Qualification Program......................................................... 24

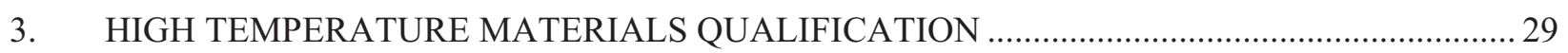

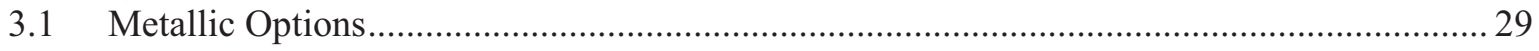

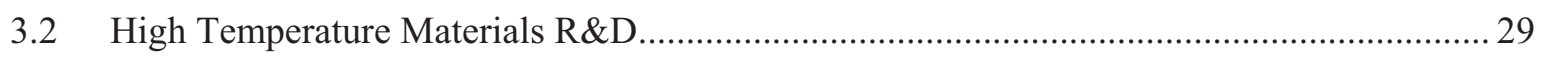

4. DESIGN AND SAFETY METHODS DEVELOPMENT AND VALIDATION........................... 33

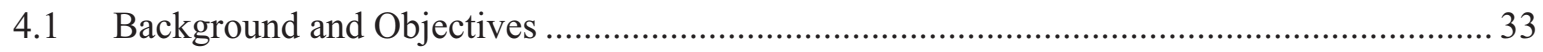

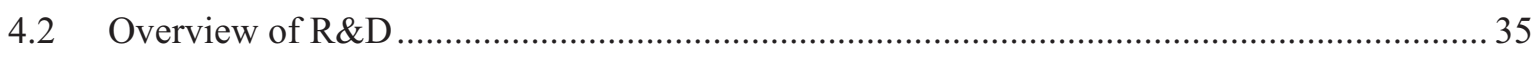

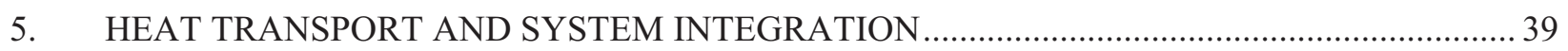

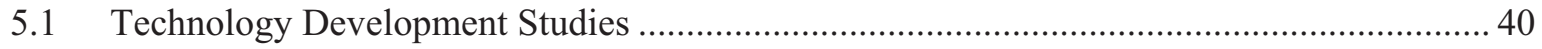

5.2 Create Component and Pilot-scale Testing Infrastructure ................................................. 41

5.3 Develop Modeling Tools and Validate through Testing and Demonstration ....................... 44

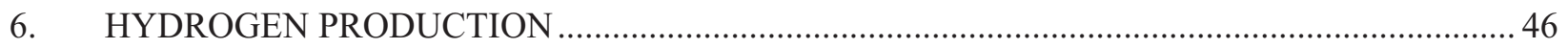

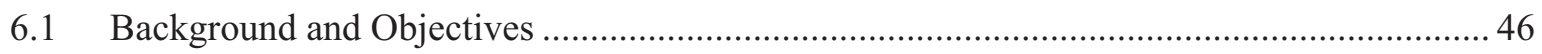

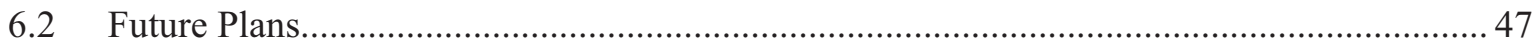

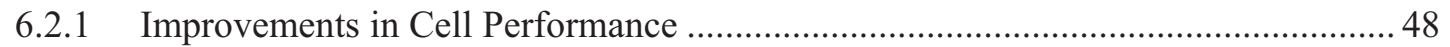

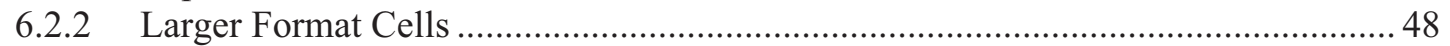

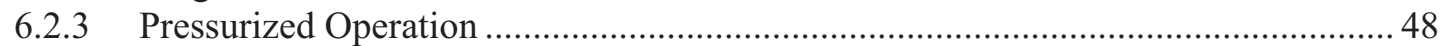

6.2.4 Scientific Understanding of Electrolytic Operation ................................................ 48

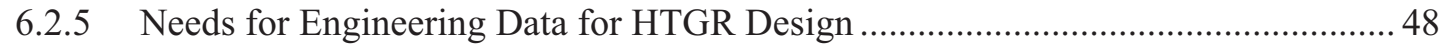

6.3 Plans for Hydrogen Production Demonstration by NGNP ............................................. 48

7. INTERNATIONAL INTEREST IN HIGH TEMPERATURE GAS REACTORS ........................ 50

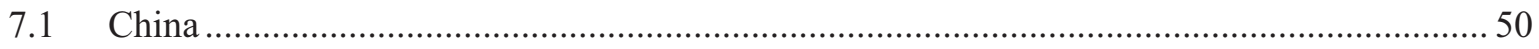

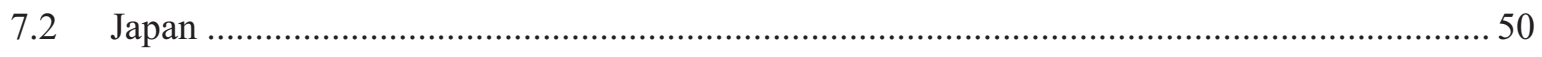

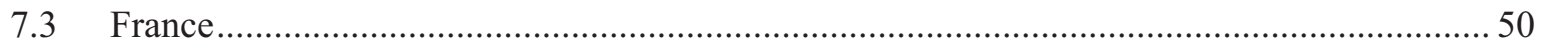




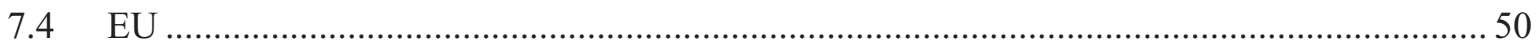

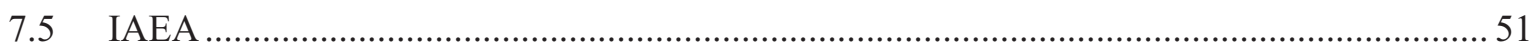

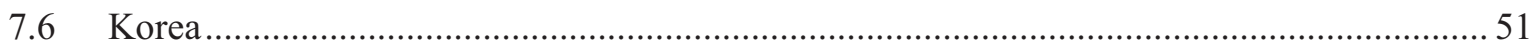

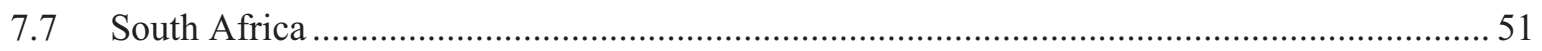

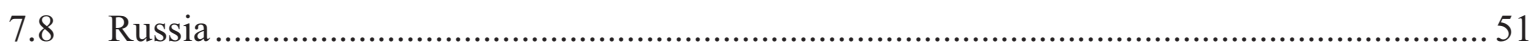

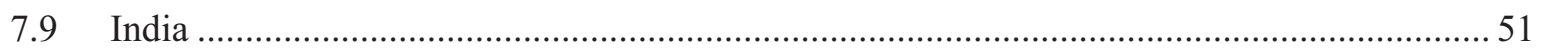

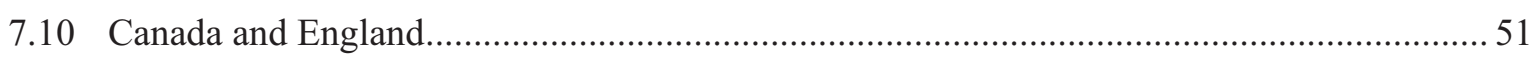

7.11 Results from Generation IV and Other Collaborative Umbrellas ....................................... 51

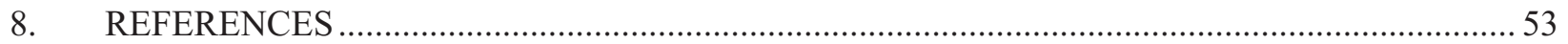




\section{FIGURES}

Figure 1. TRISO fuel and pebble-bed and prismatic-block fuel-element designs. .................................... 14

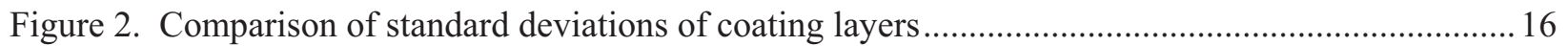

Figure 3. Radar plot of key parameters for TRISO-coated fuel performance............................................ 17

Figure 4. Comparison of gas release form AGR-1 with historic German and US data ........................... 18

Figure 5. Photos of furnaces used in accident safety testing of TRISO fuel, (a) ORNL CCCTF, (b)

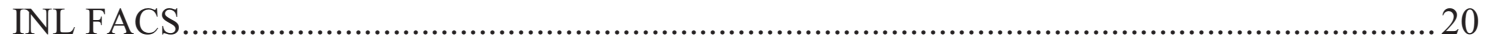

Figure 6. Fuel development and qualification program schedule .......................................................... 22

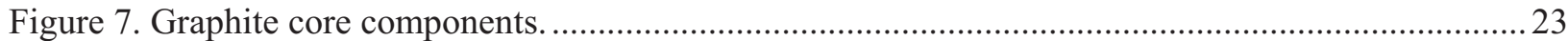

Figure 8. Graphite characterization laboratories - showing thermal and physical characterization equipment such as Laser Flash Diffusivity, thermal dilatometer (CTE measurements), Thermal Gravimetric Analysis (TGA), and ultrasonic physical measurement equipment.

Figure 9. Irradiations planned to establish the thermo-mechanical and thermo-physical response of the major grades of graphite as a function of temperature and radiation dose. ......................25

Figure 10. Photographs of AGC-1 test train during assembly..............................................................26

Figure 11. Graphite data and qualification program schedule .............................................................28

Figure 12. Examples of high temperature material testing (a) Creep fatigue testing, (b) Controlled

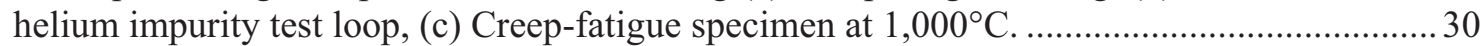

Figure 13. Mechanical response of Alloy 617 indicating tertiary creep................................................... 31

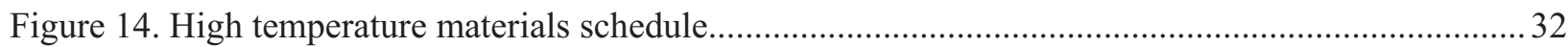

Figure 15. Experiments and computer simulations used in HTGR design and safety............................. 34

Figure 16. Multiple predictions of core power response to the withdrawal of control rods in the

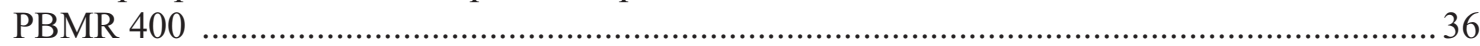

Figure 16. Fluid and Heat Transport near the core-reflector boundary of a pebble bed reactor ............... 37

Figure 18. Schematics of the HTTF at Oregon State University and the reactor cavity cool-down

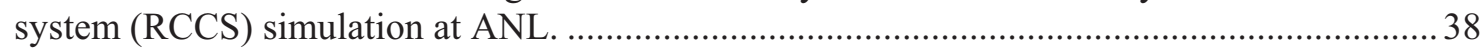

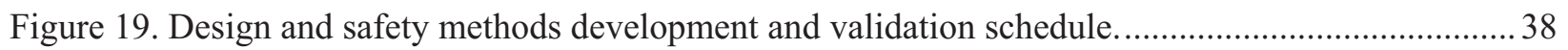

Figure 20. Examples of high temperature heat exchangers and circulators...........................................40

Figure 21. Heat Transport Component Test Capability required to mature the component

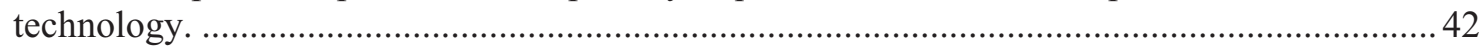

Figure 22. Diffusion bonded specimen in the Gleeble System.............................................................. 43

Figure 23. Levels of instrumentation and control development and integration. .................................... 44

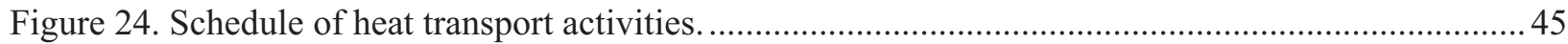

Figure 25. HTE integrated lab-scale experiment (left) and three electrolytic modules (right).................47

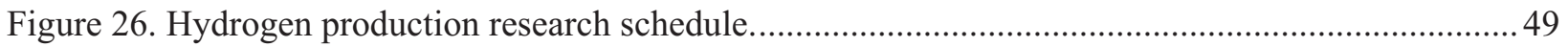




\section{TABLES}

Table 1. Comparison of defects between AGR-1 and AGR-2. Fractional defect values are 95\% confidence estimates based on sample size. 16

Table 2. Benchmarks and facilities suitable for NGNP code validation and verification..... 


\title{
ACRONYMS
}

\author{
AG-110m silver \\ AGC Advanced Graphite Capsule \\ AGR Advanced Gas Reactor \\ ANL Argonne National Laboratory \\ ANL Argonne National Laboratory \\ AR argon \\ ASME American Society of Mechanical Engineers \\ ASTM American Society for Testing and Materials \\ ATR Advanced Test Reactor \\ C carbon \\ CCCTF Core Conduction Cooldown Test Facility (ORNL) \\ CEA Commissariat à l'Énergie Atomique \\ CFD computational fluid dynamics \\ COL combined license \\ CRP Coordinated Research Project \\ DOE Department of Energy \\ dpa displacements per atom \\ EPRI Electric Power Research Institute \\ EU European Union \\ FACS Fuel Accident Condition Simulator (INL) \\ FSV Fort St. Vrain \\ GA General Atomics \\ GIF Generation IV International Forum \\ HFIR High Flux Isotope Reactor \\ HTE high temperature electrolysis \\ HTGR high temperature gas reactor \\ HTTF High Temperature Test Facility \\ HTTR High Temperature Test Reactor \\ IAEA International Atomic Energy Agency \\ IHX intermediate heat exchanger \\ ILS integrated laboratory scale \\ IMGA irradiated microsphere gamma analyzer
}


INL Idaho National Laboratory

IPyC inner pyrolytic carbon

IRPhEP International Reactor Physics Experiment Evaluation Project

ISI in-service inspection

ITU Transuranic Institute

JAERI Japan Atomic Energy Research Institute

LWR light water reactor

MISTER Mixed Stream Test Rig

NDE Non-Destructive Examination

NERI Nuclear Energy Research Initiative

NGNP Next Generation Nuclear Plant

NHI Nuclear Hydrogen Initiative

NL normal liters

NRC Nuclear Regulatory Commission

OPyC outer pyrolytic carbon

ORNL Oak Ridge National Laboratory

OSU Ohio State University

PBMR Pebble Bed Modular Reactor

PIE post-irradiation examination

PyC pyrocarbon

R\&D research and development

RCCS reactor cavity cool-down system

S-I sulfur-iodine

$\mathrm{SiC} \quad$ silicon carbide

SNL Sandia National Laboratory

SPECTR Small Pressure Cycling Test Rig

TGA Thermal Gravimetric Analysis

TRISO tri-isotropic

$\mathrm{V} \& \mathrm{~V} \quad$ verification and validation

VHTR very high temperature reactor 


\section{Research and Development Status}

At the inception of the Next Generation Nuclear Plant (NGNP) project, experts from the Department of Energy (DOE) national laboratories, gas reactor vendors, and universities collaborated to establish technology research and development (R\&D) roadmaps. These roadmaps outlined the testing and computational development activities needed to qualify the materials and validate the modeling and simulation tools to be used in the design and safe operation of the NGNP, a helium-cooled, high temperature gas reactor (HTGR). The technology development roadmaps draw on worldwide experience gained from the six demonstration and/or prototype HTGRs that have been built and operated over the past 60 years and their related technology development programs. The roadmaps include detailed descriptions of the required technical activities with associated schedules and budgets for completion of the activities and form the baseline for execution of the R\&D needed for the NGNP Project. The R\&D activities are organized into six major technical areas: (1) Fuel Development and Qualification, (2) Graphite Development and Qualification, (3) High temperature Materials Qualification, (4) Design and Safety Methods Validation, (5) Heat Transport and System Integration, and (6) Hydrogen Production. Each area's objectives, current status, accomplishments to date, and future plans are discussed in this report. To accomplish these objectives, the R\&D program draws upon expertise at DOE national laboratories, industry, and a broad array of universities along with international facilities and expertise accessible to the DOE via the Generation IV International Forum (GIF).

\section{FUEL DEVELOPMENT AND QUALIFICATION}

The HTGR concept is based on coated-particle fuels, shown in the upper left of Figure 1. Such fuels have been extensively studied worldwide over the past four decades. The tri-isotropic (TRISO)-coated particle fuel is formed by surrounding the uranium kernel (the active part of the particle) with layers of carbon (C) and silicon carbide (SiC). The HTGR would contain billions of multilayered TRISO-coated particles. Either small cylinders called "compacts" or tennis-ball-sized spheres called "pebbles" (see Figure 1) are made from carbonaceous material with the tiny particles of fuel distributed throughout.

The TRISO layers make this fuel extremely resistant to physical deterioration, thus providing robust protection for the nuclear material and outstanding retention of the radioactive material produced during fission. Extensive testing in Germany in the 1970s and 1980s demonstrated that outstanding performance of high-quality low-defect TRISO-coated particle fuels under both normal operation and potential but highly improbable accident conditions can be achieved. It is this performance combined with the passive safety features of modern modular HTGRs that allows these reactors to be located close to industrial complexes where they can provide heat for the high temperature chemical processes and hydrogen for chemical and petrochemical industries, the major objective of the NGNP project.

The objective of the Advanced Gas Reactor (AGR) Fuel Development and Qualification Program is to qualify TRISO-coated particle fuel for use in the HTGR being designed and licensed by the NGNP project. ${ }^{1}$ TRISO-coated particles must be fabricated at industrial scale, as opposed to small batches in a laboratory, for use in qualification testing. The testing consists of a variety of experiments and examinations that will allow an understanding of the behavior of TRISO-coated fuel under the radiation and temperature environment expected in an HTGR. The program also contains experiments to provide an understanding of how the fission products - the elements produced when uranium fissions - stay inside or move outside of the coated fuel particles and through the graphite reactor core (this is called the source term). Another important part of the program is the development of fuel performance and source term modeling and simulation computer tools and the associated physical testing to validate those tools for use in the NGNP design and safety analysis. A detailed discussion of fuel and source term qualification for both pebble bed and prismatic technologies was recently provided to the Nuclear Regulatory Commission (NRC) in a white paper. ${ }^{23}$ 


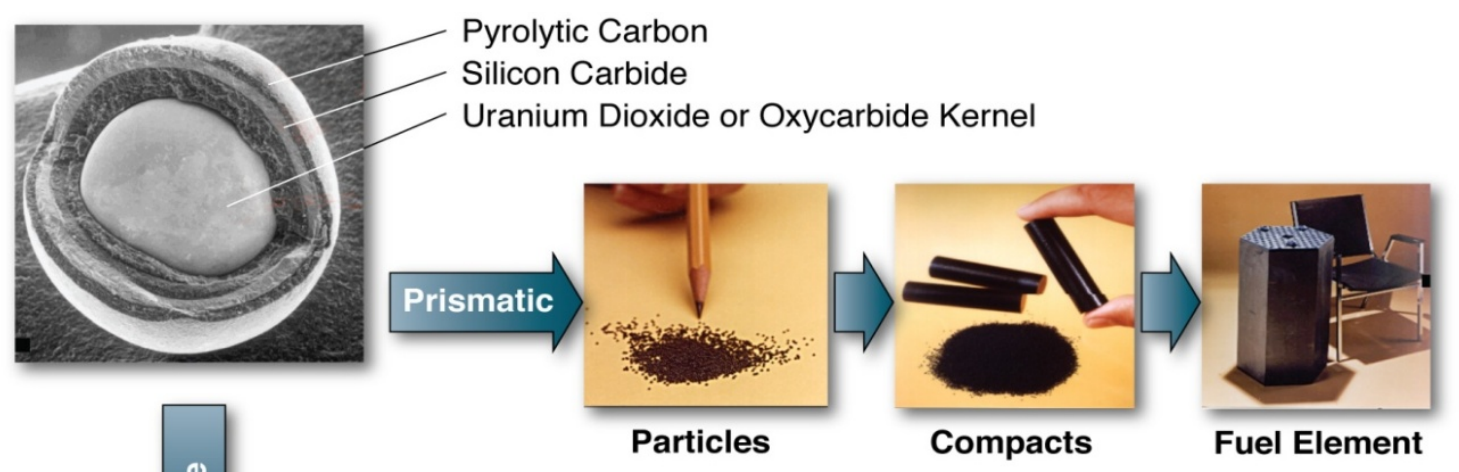

TRISO-coated fuel particles (left) are formed into fuel compacts (center) and inserted into graphite fuel elements (right) for the prismatic reactor

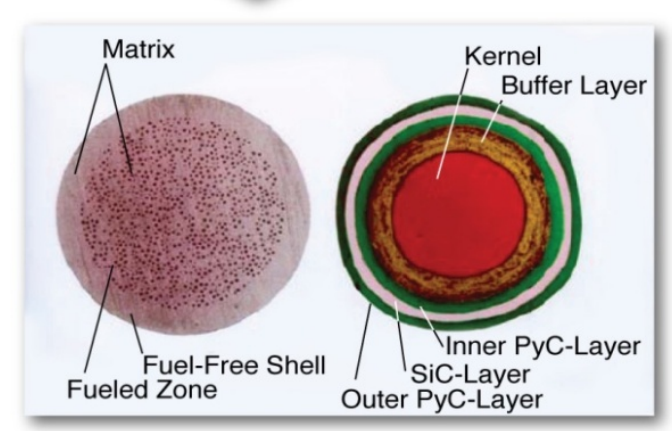

TRISO-coated fuel particles are formed into fuel spheres for pebble bed reactor

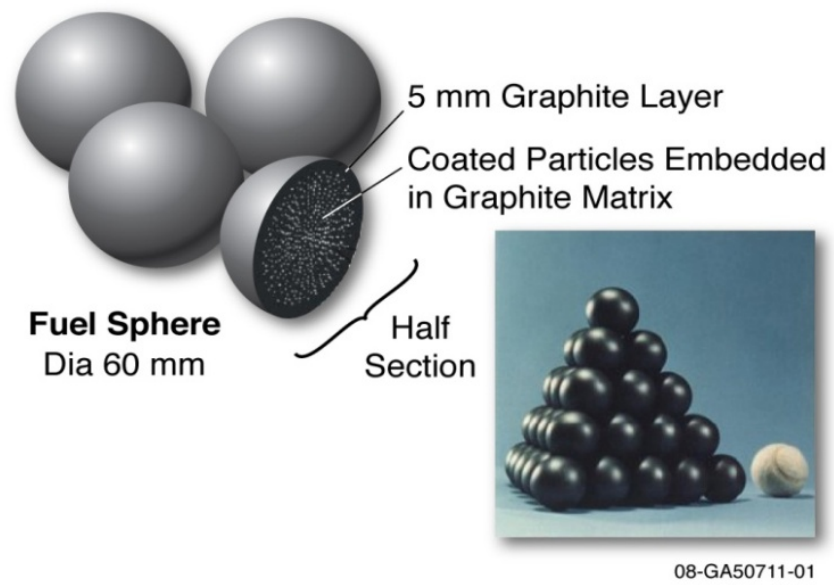

Figure 1. TRISO fuel and pebble-bed and prismatic-block fuel-element designs.

The AGR Fuel Development and Qualification Program involves five major program elements:

- Fuel manufacture

- Fuel and materials irradiation

- Safety testing and post-irradiation examination (PIE)

- Fuel performance modeling

- Fission-product transport and source term.

\subsection{Fuel Manufacture}

This element addresses the work necessary to produce coated-particle fuel that meets fuel specifications and performance requirements, and includes process development for kernels, coatings, and compacting; quality control methods development; scale-up analyses; and process documentation needed for technology transfer. This effort will produce fuel and material samples for characterization, irradiation, and accident testing as necessary to meet the overall goals. The plan also identifies work to develop automated fuel fabrication technology suitable for mass production of coated-particle fuel at an acceptable cost. 
The uranium-containing kernels are made by a sol-gel process, followed by washing, drying, and calcination to produce $\mathrm{UO}_{2}$ or $\mathrm{UCO}$ kernels. ( $\mathrm{UCO}$ is a mixture of $\mathrm{UO}_{2}, \mathrm{UC}$, and $\mathrm{UC}_{2}$.) The coatings are applied in a fluidized-bed coater in a sequential, continuous manner. The coating process for the buffer is based on chemical vapor deposition from a mixture of argon (Ar) and acetylene between 1,250 and $1,300^{\circ} \mathrm{C}$. The inner and outer pyrolytic (IPyC and $\mathrm{OPyC}$, respectively) layers are deposited from a mixture of acetylene, propylene, and argon between 1,200 and $1,400^{\circ} \mathrm{C}$. The $\mathrm{SiC}$ layer is deposited from a mixture of hydrogen or hydrogen and argon, and methyltrichlorosilane between 1,500 and $1,600^{\circ} \mathrm{C}$. Graphite powder and organic binders are used to produce a powder matrix that overcoats the particles. The overcoated particles, and additional matrix for pebble fuel, are then pressed to form the pebble or cylindrical compact. Both fuel forms undergo carbonization and heat treatment at a high temperature to produce the final fuel form.

Rigorous control is applied at every step of the fabrication process to produce high-quality, very low-defect fuel. Defect levels are typically on the order of one defect per 100,000 particles. For example, destruct fuel production for German reactors in the 1980s yielded only about 100 defects in 3.3 million particles produced. Specifications are placed on the diameters, thicknesses, and densities of the kernel and layers; the sphericity of the particle; the stoichiometry of the kernel; the isotropy of the carbon; and the acceptable defect levels for each layer. Statistical sampling techniques are used to demonstrate compliance with the specifications, usually at the $95 \%$ confidence level.

At its inception, the AGR Fuel Development and Qualification Program had to re-establish the capability to fabricate and characterize TRISO-coated particle fuel in the U.S. after about a decade long hiatus. Many of the characterization procedures and associated equipment used in the past were still available but needed to be modernized to take advantage of current measurement technology and develop qualified procedures and personnel to meet NQA-1 requirements. In some cases, e.g., PyC anisotropy, new more accurate and repeatable methods were developed. The result has been more controlled and reproducible fabrication and much more accurate and precise characterization of this fuel form. Figure 2 compares the population standard deviation of coating layer thicknesses from the lab and engineering scale coaters (AGR-1 and AGR-2) with historical US, German and Japanese data. The smaller standard deviation of the AGR fuel demonstrates the tighter process control associated with chemical vapor deposition coating and the enhanced characterization techniques that provide greater precision to the measurements. Systematic fabrication studies, combined with improved characterization capabilities, have also enhanced the understanding of how to fabricate high-quality TRISO fuel. The program is now fabricating high-quality, low-defect (about 1 defect in every 100,000 particles for defective SiC, defective IPyC and exposed uranium) TRISO-coated fuel particles in an engineering-scale coater. ${ }^{4} \mathrm{~A}$ comparison of different types of defects at lab scale for AGR-1 and at engineering scale for AGR-2 TRISO fuel is shown in Table 1. Placing a U.S. fuel vendor in position to fabricate high-quality TRISO fuel with an improved fundamental understanding of the relationships between the fuel fabrication process, fuel properties, and fuel performance enhances credibility with the NRC with respect to the safety approach for modular HTGRs. 


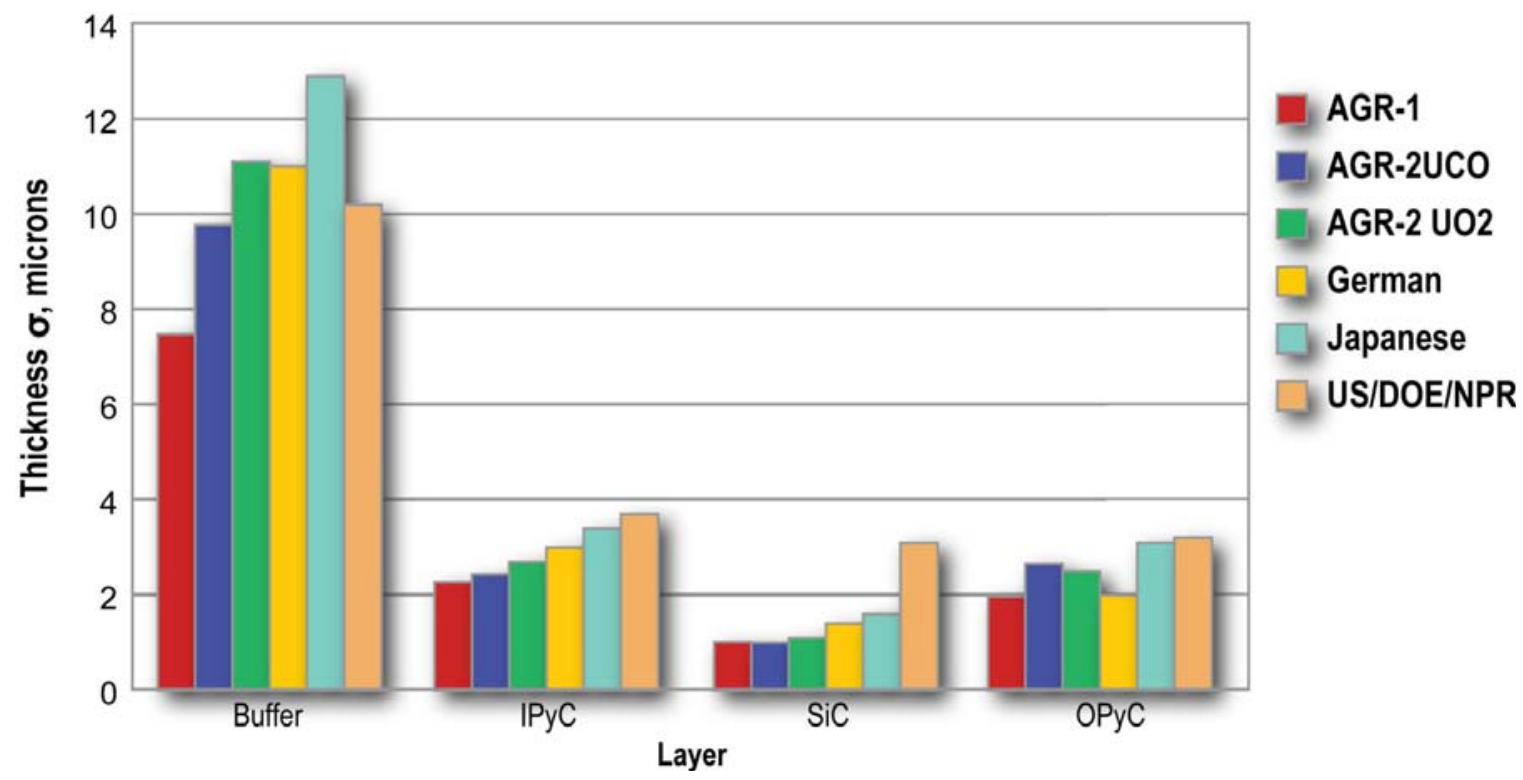

Figure 2. Comparison of standard deviations of coating layers

Table 1. Comparison of defects between AGR-1 and AGR-2. Fractional defect values are 95\% confidence estimates based on sample size.

\begin{tabular}{|c|c|c|c|c|c|c|}
\hline & AGR-1 B & AGR-1 V1 & AGR-1 V2 & AGR-1 V3 & AGR-2 UCO & AGR-2 UO2 \\
\hline \multicolumn{7}{|c|}{ At Particle Level } \\
\hline $\mathrm{SiC}$ defects & $\begin{array}{c}0 / 120,688 \\
\leq 2.5 \mathrm{E}-5\end{array}$ & $\begin{array}{c}1 / 121,117 \\
\leq 4.0 \mathrm{E}-5\end{array}$ & $\begin{array}{l}1 / 50,265 \\
\leq 9.5 \mathrm{E}-5\end{array}$ & $\begin{array}{c}1 / 120,660 \\
\leq 4.0 \mathrm{E}-5\end{array}$ & $\begin{array}{c}5 / 217,000 \\
\leq 4.8 \mathrm{E}-5\end{array}$ & $\begin{array}{c}1 / 120,000 \\
\leq 3.9 \mathrm{E}-5\end{array}$ \\
\hline \multicolumn{7}{|c|}{ Compact Level } \\
\hline Exposed U defects & $\begin{array}{l}0 / 99,470 \\
\leq 3.1 \mathrm{E}-5\end{array}$ & $\begin{array}{l}0 / 74,699 \\
\leq 4.1 \mathrm{E}-5\end{array}$ & $\begin{array}{l}0 / 99,100 \\
\leq 3.1 \mathrm{E}-5\end{array}$ & $\begin{array}{l}0 / 99,032 \\
\leq 3.1 \mathrm{E}-5\end{array}$ & $\begin{array}{c}3 / 317,625 \\
\leq 2.5 \mathrm{E}-5\end{array}$ & $\begin{array}{c}3 / 246,840 \\
\leq 3.2 \mathrm{E}-5\end{array}$ \\
\hline IPyC defects & $\begin{array}{l}0 / 49,735 \\
\leq 6.1 \mathrm{E}-5\end{array}$ & $\begin{array}{l}0 / 49,799 \\
\leq 6.1 \mathrm{E}-5\end{array}$ & $\begin{array}{l}0 / 49,555 \\
\leq 6.1 \mathrm{E}-5\end{array}$ & $\begin{array}{l}0 / 49,516 \\
\leq 6.1 \mathrm{E}-5\end{array}$ & $\begin{array}{l}0 / 64,525 \\
\leq 4.8 \mathrm{E}-5\end{array}$ & $\begin{array}{l}1 / 61,710 \\
\leq 7.7 \mathrm{E}-5\end{array}$ \\
\hline $\mathrm{SiC}$ defects & $\begin{array}{l}2 / 49,735 \\
\leq 1.3 \mathrm{E}-4\end{array}$ & $\begin{array}{l}0 / 49,799 \\
\leq 6.1 \mathrm{E}-5\end{array}$ & $\begin{array}{l}1 / 49,555 \\
\leq 9.6 \mathrm{E}-5\end{array}$ & $\begin{array}{l}0 / 49,516 \\
\leq 6.1 \mathrm{E}-5\end{array}$ & $\begin{array}{c}0 / 254,100 \\
\leq 1.2 \mathrm{E}-5\end{array}$ & $\begin{array}{c}0 / 123,420 \\
\leq 2.5 \mathrm{E}-5\end{array}$ \\
\hline
\end{tabular}

\subsection{Fuel and Materials Irradiation}

The fuel irradiation activities will provide data on TRISO-coated fuel performance under normal operation. The primary objectives include providing data, as necessary, to support fuel-process development, qualify a fuel design and fabrication process for normal operation conditions, support development and validation of fuel performance and fission-product transport models and codes, and provide irradiated fuel and materials as necessary for PIE and safety testing. 
Figure 3 is a radar plot of the important parameters for qualifying fuel performance (The dotted line signifies a request by prismatic vendor designers to utilize high packing fractions in their design. This is currently under evaluation.). The performance envelope for TRISO-coated fuel is shown in terms of five key parameters: (1) fuel temperature, (2) fuel burnup, (3) fuel fast fluence, (4) power density, and (5) particle packing fraction. Envelopes are shown for the successful German and Japanese programs established in the 1980s and 1990s, respectively, along with a prismatic NGNP design ${ }^{\mathrm{a}}$. Because a final core design for NGNP has not yet been established, a bounding envelope has been established. The irradiations in the AGR program are using this envelope to guide the irradiation testing. (The dotted line signifies a request by prismatic vendor designers to utilize higher packing fractions in their design. This is currently under evaluation.)

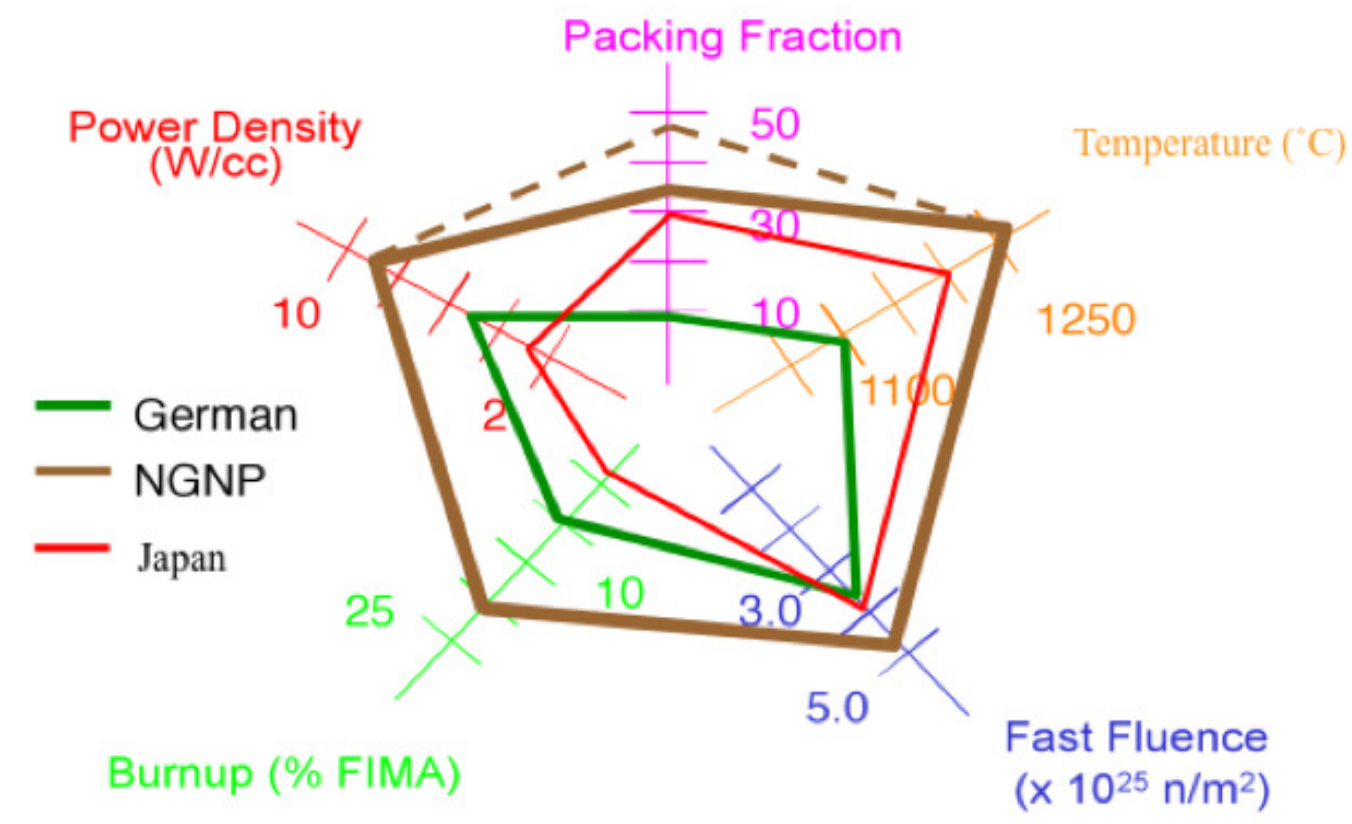

Figure 3. Radar plot of key parameters for TRISO-coated fuel performance.

A total of eight irradiation experiments were initially planned for the program. The purpose of the AGR-1 irradiation test, which used laboratory-scale fuel and has been completed, was to shake down the new multi-cell capsule design, fabrication, and operation to reduce the chances of capsule failures in subsequent irradiation tests and to provide early performance data from laboratory-scale fuel. AGR-2 will be a performance demonstration irradiation of both $\mathrm{UO}_{2}$ and UCO TRISO with fuel fabricated from an engineering-scale coater and $\mathrm{UO}_{2}$ TRISO fuel from both laboratory and production scale coaters. Feedback to the fabrication process is expected following both AGR-1 and AGR-2. In AGR-3/4, two separate planned irradiation tests will be combined into one test train to obtain data on the release of fission gases and fission metals from failed particles and their retention in the fuel compact matrix and graphite under a broad range of irradiation conditions (burnup, fluence, temperature) in support of fission product transport model development. Given the statistical nature of coated-particle fuel, a large number of fuel particles is needed to fully qualify the fuel and demonstrate compliance with the fuel-failure fraction limits. AGR-5/6 is one large irradiation that will be used to qualify the fuel for the NGNP. AGR-

\footnotetext{
${ }^{a}$ The NGNP AGR fuel program plan was established to focus primarily on prismatic fuel to balance the extensive international programs addressing pebble fuel. The current irradiation, AGR-2, contains a mixture of prismatic and pebble particle designs, and in response to recent changes in international programs the AGR fuel program may incorporate additional pebble fuel scope in the future.
} 
7 and AGR-8 are irradiations designed to provide data with which to validate fuel performance and fission-product transport models. An additional irradiation to provide data on the effects of moisture on fuel performance is under consideration if the NGNP design incorporates a steam generator in the primary system to produce process heat in the form of steam.

The first irradiation test, AGR-1, recently completed approximately three years of irradiation. The fuel in AGR-1, composed of a reference fuel and three fuel variants having different IPyC or SiC coating properties, was irradiated to a peak burnup of $19 \%$, a peak fast-neutron fluence of about $4.5 \times 10^{25} \mathrm{n} / \mathrm{m}^{2}$, and a maximum time-averaged fuel temperature of less than $1,250^{\circ} \mathrm{C}$. About 300,000 TRISO fuel particles were irradiated without a single particle failure, as indicated by the fission-gas measurements on the purge gas from each of the capsules. ${ }^{5}$ Figure 4 compares the gas release (as measured by the release to birth ratio) for AGR-1 compared with historical U.S.and German data. The gas release is very low indicative of release from contamination. This is the best irradiation performance of a large quantity of TRISO fuel ever achieved in the US, exceeding previous levels of burnup by almost a factor of 2 . These results provide a high level of confidence that the AGR fuel program will successfully demonstrate the superior performance capability of TRISO fuel required by the modular HTGR concept. Post-irradiation examination of fuel irradiated in AGR-1 is underway and safety testing will begin in late fiscal year (FY)2010.

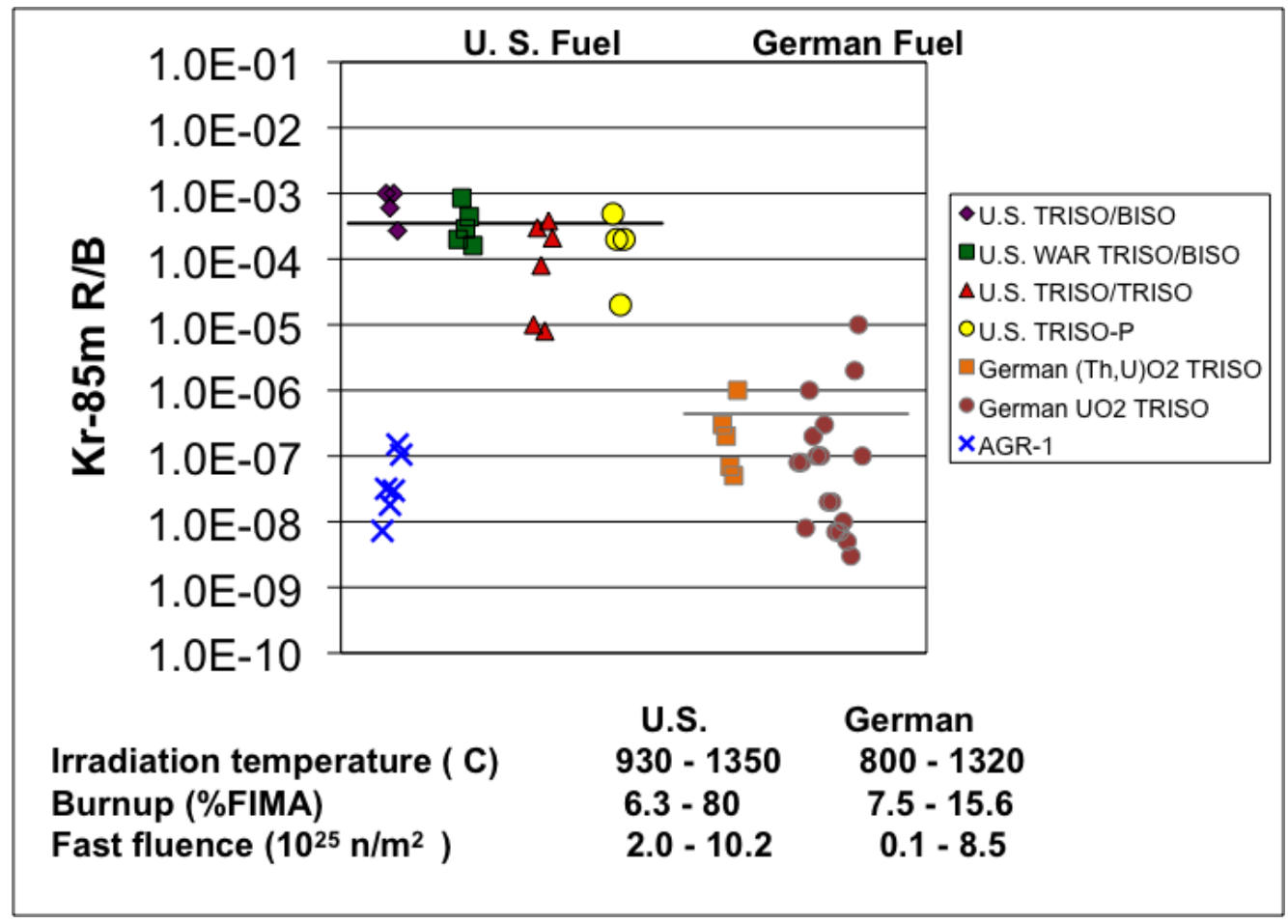

Figure 4. Comparison of gas release form AGR-1 with historic German and U.S.data

The second irradiation, AGR-2, is underway. It contains both $\mathrm{UCO}$ and $\mathrm{UO}_{2}$ TRISO produced at lab, engineering and production scale from U.S. and international collaborators (France/AREVA and South Africa/ Pebble Bed Modular Reactor [PBMR]). The UCO will be irradiated at prismatic conditions while the $\mathrm{UO}_{2}$ TRISO will experience conditions typical of a pebble-bed HTGR. The third irradiation, AGR 3/4, is in final design, and the start of irradiation is scheduled for Fall 2011. 


\subsection{Safety Testing and PIE}

This program element will provide the facilities and processes to measure the performance of TRISO fuel under normal operating and accident conditions. This work will support the fuel manufacture effort by providing feedback on the performance of kernels, coatings, and compacts. Data from PIE and accident testing will supplement the in-reactor measurements as necessary to demonstrate compliance with fuel performance requirements and support the development and validation of computer codes.

The PIE will use a variety of nondestructive and destructive techniques to characterize the state of the fuel after irradiation and after safety testing of irradiated fuel. Techniques include:

- Metrology to characterize shrinkage or swelling of the fuel

- Optical metallography to characterize the state of the kernel and coatings

- Scanning electron microscopy and microprobe to characterize distribution of fission products within the particles, including evidence of chemical attack of SiC

- Gamma scanning of the fuel and the other test components to determine fission-product migration, radionuclide inventories and burnup

- Chemical analysis via a leach-burn-leach process ${ }^{b}$ to determine fuel-particle failure fraction

- Compact deconsolidation and gamma spectral measurement of key fission products of individual particles using the irradiated microsphere gamma analyzer (IMGA) to establish fission-product retention on a particle-by-particle basis.

Traditional burnup analysis is also performed as part of the series of PIEs. Following deconsolidation, a few particles will be sent for destructive radiochemical assay to determine the concentration of transuranics and minor actinides, from which burnup can be assessed.

An important goal of this program is to determine the performance of the fuel under high temperature accident conditions because integrity of the coated particle to high temperature is a crucial part of the safety case for modular HTGRs. In particular, three environments are of interest: helium, air, and steam. The irradiated TRISO fuel will be exposed to these environments for up to 500 hours. Temperatures from 1,300 to $1800^{\circ} \mathrm{C}$ are planned to define the accident response and establish the margin of the fuel. The experimental facility will consist of a flowing-gas furnace to maintain a fuel specimen at specified temperatures with a cold finger to trap the condensable fission products and a cold trap for trapping fission gases. The cold finger and cold traps are analyzed using traditional gamma spectroscopy, and the cold finger can also be leached for radiochemical analysis. The two furnaces that will be used with flowing helium (one at Idaho National Laboratory [INL] and one at Oak Ridge National Laboratory [ORNL]) are shown in Figure 5.

The data needed from safety testing are fission-product release, TRISO-coating layer integrity, and fission-product distribution within fuel particles (fission-product attack of the SiC layer) and fuel compacts. Apparatus to perform safety tests in oxidizing atmospheres will be developed later in the program. The anticipated release behavior of the fission products is somewhat different than in other nuclear fuels. For intact particles, silver $(\mathrm{Ag}-110 \mathrm{~m})$ is released first because of its greater mobility through the $\mathrm{SiC}$ coating of the TRISO particle fuel. This is followed by Cs-134 and Cs-137, which can diffuse through the pyrocarbon $(\mathrm{PyC})$ and $\mathrm{SiC}$ layers after long times at these temperatures. Last, because of holdup by PyC layers, the fission gas $\mathrm{Kr}-85$ is released. PIE following elevated temperature safety tests

b. In this technique, the fuel compact or pebble is leached with acid to remove any fission metals (e.g., cesium) released from defective fuel particles and heavy-metal contamination. The fuel element is then burned in air to remove all carbon matrix material, the OPyC layers, and also the IPyC/buffer layers of any particles with failed SiC. Particles that remain are then leached with an acid solution to remove any exposed uranium that had been enclosed by an intact pyrocarbon layer. The measurement of the free uranium is then converted to a SiC defect fraction. 
similar to that after irradiation is also planned. At the time of this writing, PIE of AGR-1 is underway, and a limited number of accident safety tests have been completed.

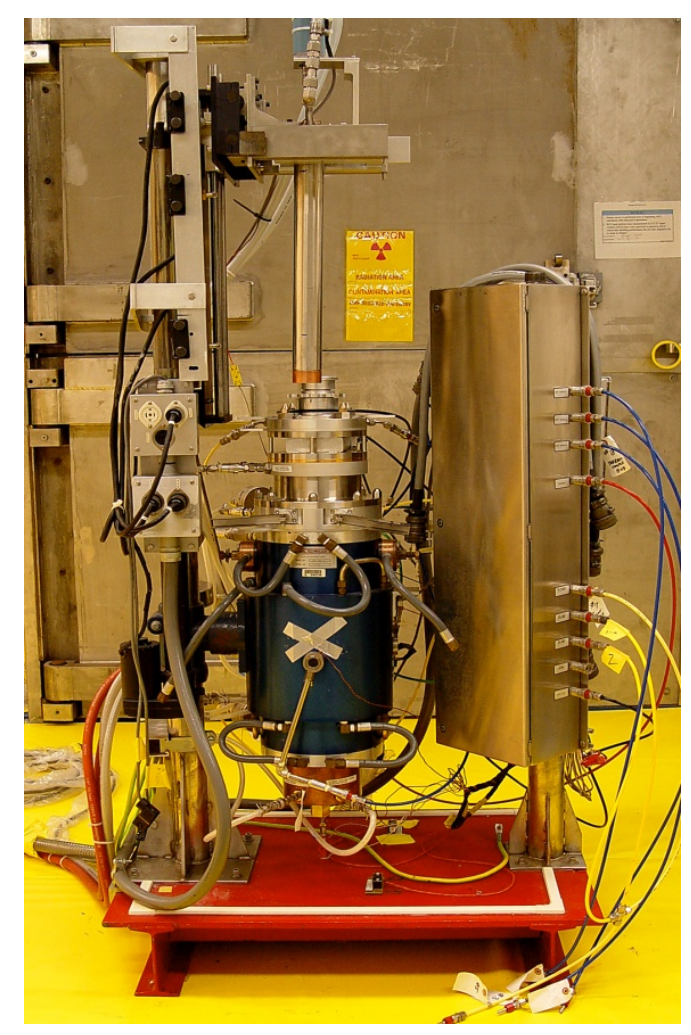

(a)

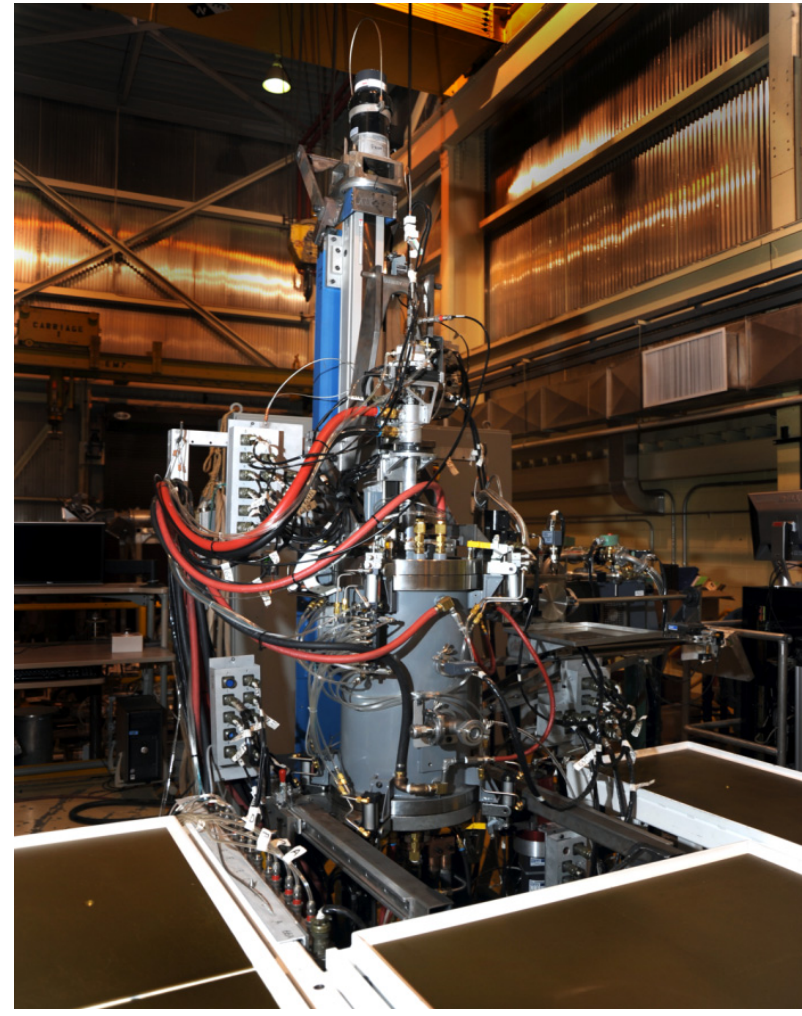

(b)

Figure 5. Photos of furnaces used in accident safety testing of TRISO fuel, (a) ORNL Core Conduction Cooldown Test Facility (CCCTF), (b) INL Fuel Accident Condition Simulator (FACS).

\subsection{Fuel Performance Modeling}

Fuel-performance modeling addresses the structural, thermal, and chemical processes that can lead to coated-particle failures. It also addresses the release and transport of fission products from the fuel kernel, through the coatings and matrix to the reactor coolant system. Physical models and computer programs have been developed and will be validated as necessary to support fuel fabrication process development and plant design and licensing.

New models are currently being developed in the U.S. that represent a first-principles-based mechanistic, integrated, thermal-mechanical-physio-chemical-irradiation performance model for particle fuel, which has the proper dimensionality yet captures the statistical nature and loading of the fuel. The mechanistic model for coated-particle fuel considers both structural and physio-chemical behavior of a particle-coated fuel system during irradiation. The INL model is called Particle Fuel Model PARFUME.6 The PARFUME model has been extensively compared to similar tools developed by international colleagues as part of an effort under the auspices of the International Atomic Energy Agency (IAEA). Successful benchmarking of the fuel-performance model has resulted in NRC's desire to use the model as part of their activities in confirming the results from other simulations. Irradiations of the specific coatings are also planned to better characterize the key material properties necessary to calculate fuel 
performance, including irradiation-induced creep of $\mathrm{PyC}$, strength of $\mathrm{SiC}$ and $\mathrm{PyC}$, and other thermomechanical properties.

\subsection{Fission Product Transport and Source Term}

This element will address the transport to the exclusion area boundary of fission products produced within the coated particles to provide a technical basis for radiological source terms for HTGRs under normal and accident conditions. The fission-product behavior task will provide primary source-term data needed for licensing. The technical basis will be codified in design methods (computer models) validated by experimental data as necessary to support plant design and licensing. Currently testing is underway to evaluate the permeation of tritium through potential high temperature metallic alloys anticipated at the high outlet temperatures in HTGRs.

\subsection{Fuel Acquisition and Qualification Strategy}

A fuel acquisition strategy was established in $2007 .^{7}$ In that report, a detailed technical assessment of potential fuel vendors for the first core of NGNP was conducted by an independent group of international experts based on input from the three major reactor vendor teams. Part of the assessment included an evaluation of the credibility of each option, along with a cost and schedule to implement each strategy compared with the schedule and throughput needs of the NGNP project. While credible options were identified, many changes in the assumptions underlying the strategy and in externalities that have happened in the interim require that the options be re-evaluated once the preliminary design activities in Phase II are underway.

In terms of fuel testing activities required for qualification, initial ideas for the configuration of the AGR 5/6 qualification irradiation are being developed. While the concept developed in the original AGR program plan was based on prismatic UCO fuel to complement the large program that was underway and planned in South Africa, China, and Europe for $\mathrm{UO}_{2}$ pebble fuel, recent developments (shift of the program in Europe away from HTGR R\&D and concern about PBMR's financial viability) has required a re-assessment of options for the qualification tests, AGR-5/6. Two options are under consideration: (1) if a decision on reactor type is made in the near term, a full prismatic or a full pebble qualification irradiation (and follow-on safety testing) can be accommodated or (2) a hybrid capsule in which half the test train is devoted to pebbles and half is devoted to compacts in the event both technologies continue to be pursued through preliminary design. In either case for the pebble, additional testing would probably be needed to develop an adequate statistical database on pebble fuel performance. The amount of testing depends on the degree to which the historical German pebble fuel data are relied upon in licensing. The German data were not developed under an NQA-1 program, and the ability to qualify these data is open to question at this time. Given the schedule for NGNP, and the limited irradiation locations in the U.S. to handle the large pebble fuel form, the additional irradiations would probably have to be carried out in the HFR in Petten and the safety tests at the Transuranic Institute (ITU) in Karlsruhe, Germany to meet the NGNP deployment schedule. The risks, costs, and schedules of these options are under study.

\subsection{Fuel Development and Qualification Program Schedule}

A detailed resource-loaded activity-based schedule for the activities presented in the technical program plan for TRISO fuel has been developed and is used to guide and prioritize activities year by year. A higher-level summary of that schedule is shown in Figure 6. The critical path for the fuel qualification is through the irradiations early in the program and then shifts to the postirradiation examination and safety testing later in the program. Irradiation durations are determined by their location in the Advanced Test Reactor (ATR). AGR-1 and AGR-2 are longer irradiations because of the lower thermal flux in the respective irradiation positions. AGR-3/4 through 7/8 are shorter irradiations because they will be located in a higher flux position in the ATR. The durations for postirradiation examination and safety testing are based on (a) estimates of throughputs at ORNL and INL based on the scope of 
anticipated activities considering historical and current experience in Germany and Europe for safety testing, (b) anticipated learning curve effects for the safety testing and PIE of later capsules and (c) schedule overlaps in the safety testing and PIE related activities for fuel from each of these capsules. Based on the schedule, the fuel for NGNP is anticipated to be qualified by mid-2022 assuming the funding levels required to accomplish the tasks is made available.

\begin{tabular}{|c|c|c|c|c|c|c|c|c|c|c|c|c|c|c|c|c|c|c|c|}
\hline Activity Name & $\begin{array}{l}\text { Start } \\
\text { Date }\end{array}$ & $\begin{array}{c}\text { Finish } \\
\text { Date }\end{array}$ & 03 & & 050 & & 17080 & 0910 & 11 & 12 & 13 & 14 & 15 & 16 & 171 & 81 & & & 222 \\
\hline AGR-1 Irradiation - Shakedown Small Coater Fuel & $12 / 1 / 06$ & $11 / 2000$ & & & & & 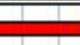 & & & & & & & & & & & & \\
\hline AGR-1 PIE and Safety Testing & $3 / 1 / 10$ & $11 / 8 / 12$ & & & & & & प्म & & & & & & & & & & & \\
\hline AGR-2 Design and Fuel Fabrication & $1 / 1,08$ & $1 / 1 / 10$ & & & & & 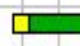 & 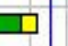 & & & & & & & & & & & \\
\hline $\begin{array}{l}\text { AGR-2 Irradiation - Pilot Scale Coater Fuel Performance } \\
\text { (West B) }\end{array}$ & $6 / 23 / 10$ & $3 / 26 / 13$ & & & & & & & & & 8 & & & & & & & & \\
\hline AGR-2 PIE and Safety Testing & $3 / 27 / 13$ & $4 / 19 / 16$ & & & & & & & & & पा & & & $\square$ & & & & & \\
\hline AGR-3/4 Design and Fuel Fabrication & $10 / 108$ & $9 / 30 / 11$ & & & & & $\square$ & + & 7 & & & & & & & & & & \\
\hline $\begin{array}{l}\text { AGR-3/4 Irradiation - Fission Product Transport Data } \\
\text { (NEFT) }\end{array}$ & $10 / 4 / 11$ & $4 / 29 / 13$ & & & & & & & & & & & & & & & & & \\
\hline AGR $3 / 4$ PIE and Safety Testing & $4 / 30 / 13$ & $2 / 28 / 17$ & & & & & & & & & $\square$ & & & & & & & & \\
\hline AGR-M Design and Fuel Fabrication & $7 / 12 / 11$ & $5 / 16 / 13$ & & & & & & & प् & & $\square$ & & & & & & & & \\
\hline AGR-M Irradiation - Moisture (Large B) & $5 \pi / 13$ & $10 / 17 / 16$ & & & & & & & & & & E & & & & & & & \\
\hline ATR Core Internals Changeout (irradiation blackout) & $9 / 1 / 14$ & $3 / 31 / 15$ & & & & & & & & & & 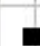 & & & & & & & \\
\hline AGR 5/6 Design and Fuel Fabrication & $10 / 1 / 10$ & $3 / 31 / 15$ & & & & & & & & & - & & ] & & & & & & \\
\hline AGR-5/6 Irradiation - Fuel Qualification (NEFT) & $8 / 10 / 15$ & $3 / 8 / 17$ & & & & & & & & & & & & $\longrightarrow$ & & & & & \\
\hline AGR 5/6 and M PIE and Safety Testing & $3 / 8 / 17$ & $2 / 10 / 20$ & & & & & & & & & & & & & & & & & \\
\hline AGR 7/8 Design and Fuel Fabrication & $8 / 2 / 12$ & $4 / 20 / 15$ & & & & & & & & प & & & ב & & & & & & \\
\hline $\begin{array}{l}\text { AGR-7/8 Irradiation Fission Product Transport V\&V } \\
\text { (NEFT) }\end{array}$ & $3 / 6 / 17$ & $9 / 28 / 18$ & & & & & & & & & & & & & & & & & \\
\hline AGR 7 \& 8 PIE and Safety Testing & $10 / 1 / 18$ & $10 / 25 / 21$ & & & & & & & & & & & & & & & E & $\square$ & \\
\hline $\begin{array}{l}\text { Out of Pile Fission Product Transport Loop Testing } \\
\text { (Plateout, Liftoff) and Integral Validation }\end{array}$ & $2 / 29,08$ & $11 / 30 / 21$ & & & & & & & & & & & & & & & & & \\
\hline $\begin{array}{l}\text { Fuel Performance Modeling - Code Development, } \\
\text { Historical Benchmarking and Constitutive Data }\end{array}$ & $3 / 3 / 03$ & $11 / 30 / 16$ & & & & & & & & & & & & & & & & & \\
\hline V\&V of Fuel Performance Code & $11 / 1 / 16$ & $8 / 29 / 20$ & & & & & & & & & & & & & & & & & \\
\hline $\begin{array}{l}\text { Fission Product Transport and Source Term Data } \\
\text { Development }\end{array}$ & $5 / 1,03$ & $10 / 31 / 16$ & & & & & & & & & & & & & & & & & \\
\hline Fission Product Transport and Source Term Code V\&V & $12 / 1 / 16$ & $8 / 30 / 20$ & & & & & & & & & & & & & & & & & \\
\hline $\begin{array}{l}\text { Key Milestone 1: Preliminary NRC Topical on Fuel } \\
\text { Performance (AGR-1 PIE and AGR-2 Irradiation) }\end{array}$ & $1 / 1 / 13$ & & & & & & & & & & & & & & & & & & \\
\hline $\begin{array}{l}\text { Key Milestone 2: Final NRC Topical on Fuel } \\
\text { Performance(AGR } 3,4,5 \text {, and } 6 \text { ) }\end{array}$ & $4 / 1 / 20$ & & & & & & & & & & & & & & & & & & \\
\hline Key Mllestone 3: VHTR Source Term Validated & $5 / 2 / 22$ & & & & & & & & & & & & & & & & & & $\nabla$ \\
\hline Key Milestone 4: Fuel Performance Model Validated & $6 / 1 / 22$ & & & & & & & & & & & & & & & & & & F \\
\hline
\end{tabular}

Figure 6. Fuel development and qualification program schedule 


\section{GRAPHITE DEVELOPMENT AND QUALIFICATION \\ $2.1 \quad$ Background}

In HTGRs, graphite physically contains the fuel and comprises the majority of the core volume. It also forms the inner and outer reflector (non-fueled) regions of the core. Graphite has been used effectively in the past as a structural and moderator material in both research and commercial high temperature gas cooled reactors, establishing graphite as a viable structural material for high temperature reactor cores (see Figure 7).
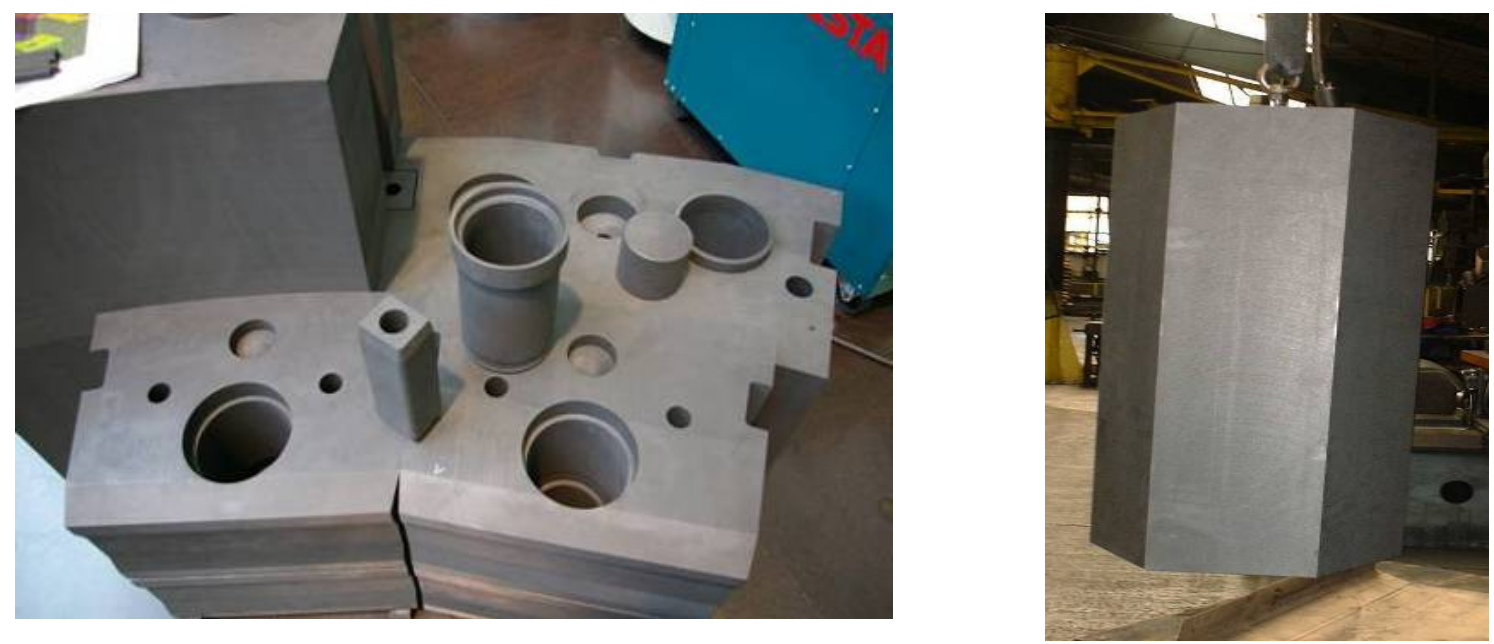

Figure 7. Graphite core components.

However, while the general characteristics necessary for fabricating available graphite are understood, the specific performance of currently available nuclear-grade graphite at the anticipated operating conditions is unknown. Previous nuclear-grade graphite, such as H327 and H451 used in Fort St. Vrain (FSV), required an extensive development program that covered both fabrication processes and actual performance data to determine if they were suitable for reactor applications. Unfortunately, historical nuclear grades are no longer produced, and the raw feedstock material (e.g., petroleum and pitch coke) used to fabricate the graphite is no longer available from the sources historically used. Thus, the new graphite grades and associated fabrication processes must be qualified. The approach to qualification outlined here is consistent with historical assessments of graphite qualification needs identified by gas reactor vendors, the NRC, and the American Society of Mechanical Engineers (ASME). The approach also factors in international experience, particularly in the U.K. where the current incomplete understanding of in-pile graphite behavior in British gas cooled reactors is causing the British utility to gather such data to respond to regulatory inquiries about the safety of those reactors in light of unexplained cracks found in graphite during reactor operation.

The new graphite grades will use new sources of unique petroleum and pitch coke in fabrication processes established previously. There is no irradiation experience with these new graphite types, so there is currently no way to quantitatively predict how they will actually perform within a reactor environment. While the graphite will be structurally stable for some period of time, the lifetime (as a function of dose and temperature) of the current grades of graphite is unknown. This is a critical safety issue in that the stability of the graphite must be understood to determine the structural safety of the internal core. Therefore, the new graphite grades need to be characterized to demonstrate that they exhibit acceptable non-irradiated and irradiated thermo-mechanical and thermo-physical performance.

Fortunately, the technology for fabricating nuclear-grade graphite has been established, and a number of graphite types are commercially available for testing and qualification. 


\subsection{Graphite Development and Qualification Program}

As part of the acquisition strategy for graphite, ${ }^{8}$ four major graphite grades from four vendors around the world (Graftec and Mersenin the U.S., SGL in Europe, and Toyo Tanso in Japan) suitable for use within both a pebble bed and prismatic HTGR design have been selected for further evaluation. Minor grades and historical samples have also been incorporated into the program to help further elucidate the impact of fabrication processes and coke sources on the resulting microstructure of the graphite and its performance under irradiation. Major grades include NBG-18 (SGL), PCEA (GrafTech Inc.), IG-110 (Toyo Tanso), and 2114 (Mersen, formerly known as Carbonne Lorraine) while minor grades include PGX, HLM, PCIB, NBG-17, IG-430, and others.

Thus, the objective of the graphite program is to develop the qualification data set of thermo-mechanical and thermo-physical properties for unirradiated and irradiated candidate grades of graphite for HTGRs. ${ }^{9}$ Where practical, other grades of graphite may be tested/characterized to provide a baseline for comparison or to help understand material property changes for the graphite grades. These activities will demonstrate the performance of various graphite types, including irradiation dose levels, anticipated applied stress levels, and maximum core temperatures.

The program consists of statistical characterization of unirradiated graphite material properties to establish the lot-to-lot, billet-to-billet, and within-billet variability of the material. This characterization will establish a quantitative baseline of material properties from which changes under irradiation can be understood. Significant effort has gone into establishing the analytical measurement laboratories (see Figure) required to perform the extensive characterization of nuclear graphite under consideration for HTGRs being developed by the NGNP project. This task consisted of procuring, setting up, and calibrating state-of-the-art analytical testing equipment and developing protocols and testing methods to make accurate, repeatable measurements on graphite. An extensive characterization effort is currently underway at INL and ORNL laboratories (see Figure 8) to establish the material properties before irradiation on a series of large graphite chunks or blocks, called billets, from the four major grades selected.
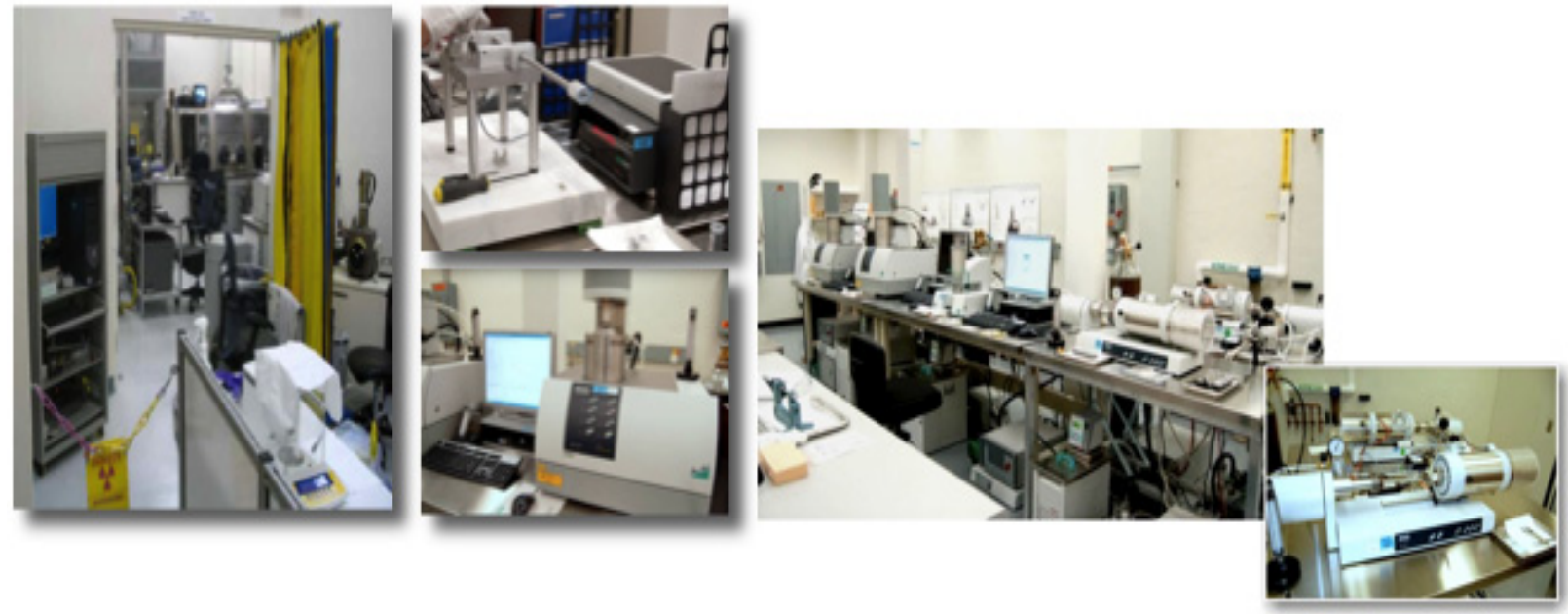

Figure 8. Graphite characterization laboratories - showing thermal and physical characterization equipment such as Laser Flash Diffusivity, thermal dilatometer (CTE measurements), Thermal Gravimetric Analysis (TGA), and ultrasonic physical measurement equipment.

Variability of key non-irradiated material properties can be as low as 3\% and as high as a factor of 4 depending on graphite grade and the specific material property. Irradiation will further degrade some of the key properties (e.g., thermal conductivity, density). The large variability must be accounted for in the 
associated design rules and material property data sets used for graphite mechanical design and safety analysis.

The historic thermo-mechanical and thermo-physical irradiation performance database of graphite focused largely on moderate doses ( 5 to 7 displacements per atom [dpa]) and modest temperatures (400 to $850^{\circ} \mathrm{C}$ ), which is typical of the design service conditions of FSV and the older German pebble-bed reactors. There are much less data at the higher temperatures and higher doses anticipated for the higher temperature designs. For prismatic designs, peak graphite temperatures could be as high as 1,000 to $1,250^{\circ} \mathrm{C}$ and the expected peak graphite doses in the reflectors could be 5 to 6 dpa with operation service lifetimes of about 6 to 10 years. A series of eight irradiations are planned to establish the thermo-mechanical and thermo-physical response of the major grades of graphite as a function of temperature and radiation dose (see Figure 9). Advanced Graphite Capsule (AGC)-1 through AGC-6 will be conducted at INL's ATR to establish the behavior of graphite in the temperature/dose envelope for NGNP. HTV-1 and HTV-2 will be conducted in the High Flux Isotope Reactor (HFIR) at ORNL to establish graphite behavior under accelerated temperature and damage conditions so that AGC-6 can be designed properly, accounting for shrinkage/swelling and creep anticipated at the high temperature and high dose. These irradiations will contain specimens of sufficient size, number, and type to support statistical assessments necessary to capture the inherent variability in graphite; to support traditional American Society for Testing and Materials (ASTM) requirements for sample analysis; and to more completely characterize the physical, thermal, and mechanical properties of the irradiated graphite. As of this writing, the first graphite capsule, AGC-1, is nearing completion. A schematic of the test train is shown in Figure 10. Over 400 samples of graphite are under irradiation.

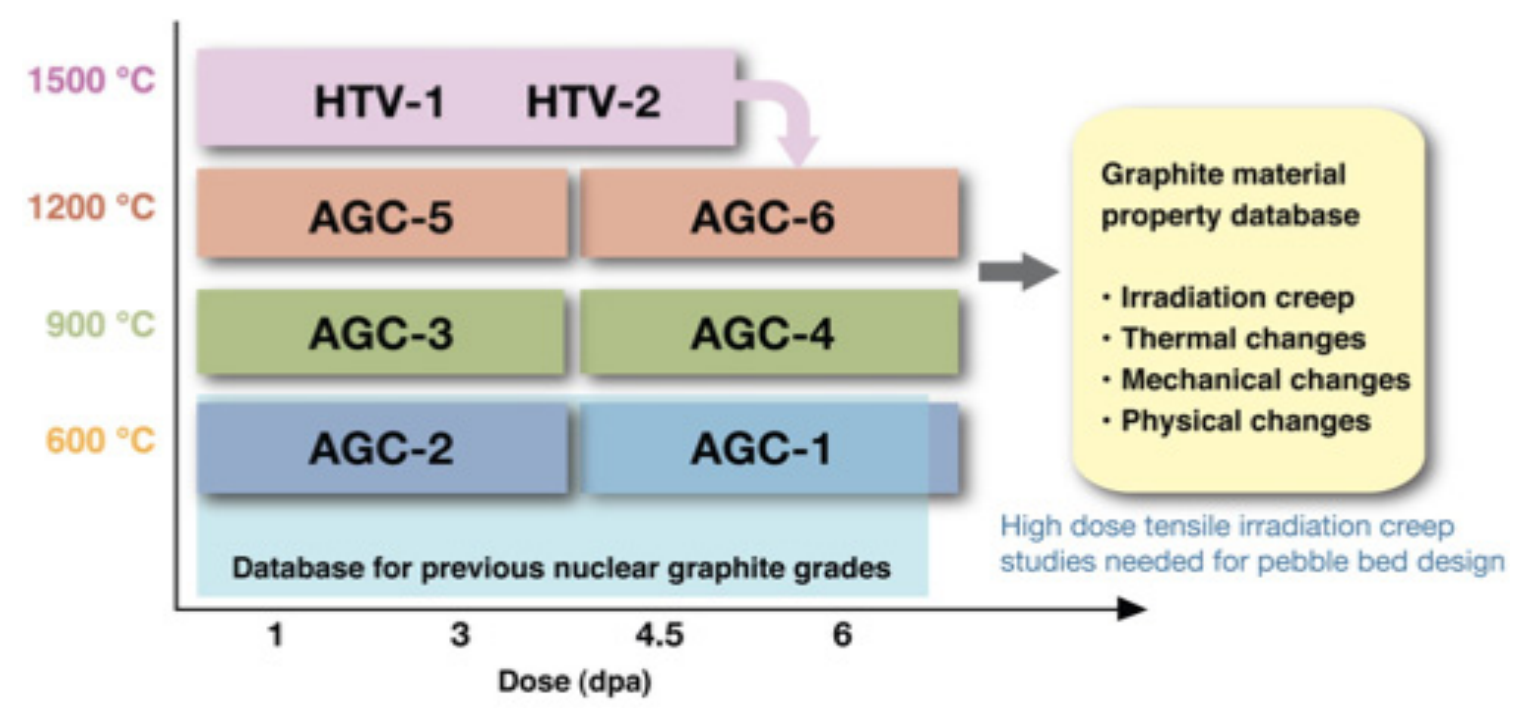

Figure 9. Irradiations planned to establish the thermo-mechanical and thermo-physical response of the major grades of graphite as a function of temperature and radiation dose. 


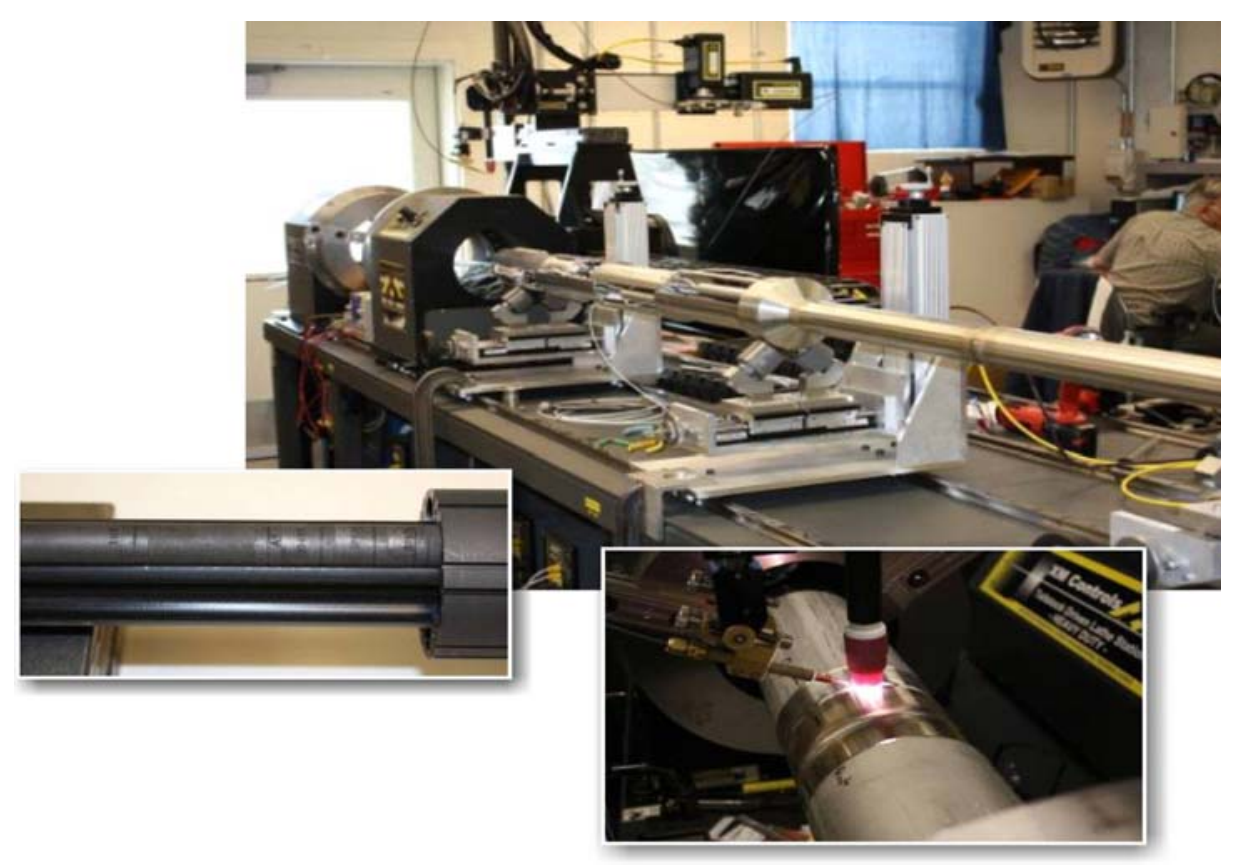

Figure 10. Photographs of AGC-1 test train during assembly.

The technology needs to satisfy requirements for the pebble bed are anticipated to be somewhat more substantial. While lower peak graphite temperatures of 1,000 to $1,100^{\circ} \mathrm{C}$ are expected, much higher doses are anticipated (20-25 dpa) because of the vendor's desire to make the reflector a facility lifetime or near-lifetime (changed once during the life) component. Thus, the new graphite grades need to be fabricated and characterized at these conditions to demonstrate acceptable performance within the more demanding environment. For a pebble-bed HTGR, additional irradiations would be needed to address the behavior of the graphite at higher dose, which could be accommodated (at additional cost) in the current graphite irradiation program.

Extensive post-irradiation characterizations are planned to establish the change in relevant material properties as a function of temperature and neutron dose. A complete properties database for these new grades of graphite is required to describe the graphite's physical, mechanical, and oxidation properties. Of particular interest is the graphite's irradiation-induced creep, which is critical to determining the lifetime of the graphite under irradiation. From these data sets, constitutive relations will be established for use in a detailed predictive thermo-mechanical finite element model. Moreover, the data must be statistically sound and take account of in-billet, between billets, and lot-to-lot variations of properties. These data are needed to support the ongoing development of the risk-derived ASME graphite design code (a consensus code being prepared under ASME's jurisdiction by gas cooled reactor stakeholders including the vendors). ASME codification of graphite will ease acceptance of this material for use by the NRC and reduce the risk to the reactor designer by establishing a safe operating envelope for graphite. A detailed discussion of graphite qualification was recently provided to the NRC in a white paper. ${ }^{10}$

Beyond the near-term graphite qualification program, a more complete evaluation of the fabrication parameters and raw material constituents' influence on graphite behavior will be required for full commercialization of the nuclear-grade graphite technology in the long term. In addition, appropriate graphite recycling and disposal options must be considered to reduce the waste volume and the attendant costs of disposal. Recycle is considered as a long-term strategy and would only be pursued by vendors when large numbers of gas reactors are deployed. The magnitude of the R\&D program necessary to establish a standard nuclear-grade graphite, whether from a new coke source and/or from recycled material for use within any HTGR design, cannot be firmly estimated today given (a) the insufficient 
knowledge of the linkage between graphite fabrication, material properties, and in-reactor performance, (b) the more aggressive anticipated operating conditions for the high temperature process heat applications, and (c) issues related to long-term source availability and variability. It is anticipated that the work proposed to qualify graphite for the initial HTGR cores will provide the strong technical basis needed to establish a long-term graphite development and qualification program that meets these more ambitious commercialization goals.

A detailed resource-loaded activity-based schedule for the activities presented in the technical program plan for graphite has been developed and is used to guide and prioritize activities year by year. A higher-level summary of that schedule is shown in Figure 11. The critical path for graphite qualification is through the irradiations. Postirradiation characterization will be performed at INL and ORNL to complete the large number of characterization activities and not impact the critical path. Assuming the funding levels required to accomplish the tasks is made available, the schedule shows that the graphite for NGNP will be qualified by 2021.

As of this writing, the baseline statistical characterization of the thermo-mechanical and thermo-physical properties of one large billet of one of the major graphite grades is complete, and characterization for a billet of a second grade is underway. Characterization of the 425 samples in both AGC-1 and AGC-2 prior to irradiation is also complete. The first capsule, AGC-1, is complete, and irradiation of the second capsule, AGC-2, has just begun. PIE of the AGC-1 graphite samples has just started. Extensive studies on graphite-air oxidation have been completed to better understand mechanisms of oxidation as a function of temperature, microstructure and air concentration to support both chronic oxidation concerns and accident safety evaluations. Advanced failure models for graphite have been evaluated based on measurements of graphite in complex combinations of potential multi-axial stress states. Finally, a code case for graphite has been sent to ASME for initial review and approval. A comprehensive Non-Destructive Examination (NDE) program is being initiated to address both the flaws in as-fabricated large graphite components as well as to develop new in-situ inspection (ISI) techniques, which will be important to monitoring the actual behavior of the core components in the reactor. Finally, multiple fundamental studies (through the NEUP program and international collaborations such as IAEA) have been initiated to better understand the damage mechanisms and behavior of graphite under irradiation. This improved understanding of the fundamental principles underlying the behavior of graphite is being used to assist in the formation of sophisticated analytical models to better predict the graphite behavior while in reactor. These models and increased understanding are also being used to develop an ASME design code for use of graphite in nuclear applications. This new design code has recently been approved by the ASME and will be included in the new ASME design code by the summer of 2011. 


\begin{tabular}{llll}
\hline Activity & Start & Finish & 070809101112131415161718192021 \\
\hline AGC-1 Design and Fabrication & $01 / 01 / 08$ & $04 / 30 / 09$ \\
\hline AGC-1 Irradiation & $09 / 08 / 09$ & $03 / 07 / 11$ \\
\hline AGC-1 PIE & $05 / 31 / 11$ & $11 / 14 / 13$ \\
\hline AGC-2 Design and Fabrication & $03 / 01 / 10$ & $03 / 30 / 11$ \\
\hline AGC-2 Irradiation & $03 / 10 / 11$ & $02 / 06 / 12$ \\
\hline AGC-2 PIE & $02 / 07 / 12$ & $08 / 11 / 14$ \\
\hline AGC-3 Design and Fabrication & $09 / 01 / 10$ & $10 / 19 / 11$ \\
\hline AGC-3 Irradiation & $02 / 07 / 12$ & $01 / 07 / 13$ \\
\hline AGC-3 PIE & $01 / 08 / 13$ & $06 / 05 / 15$ \\
\hline AGC-4 Design and Fabrication & $07 / 01 / 11$ & $09 / 29 / 12$ \\
\hline AGC-4 Irradiation & $01 / 18 / 13$ & $12 / 09 / 13$ \\
\hline AGC-4 PIE & $03 / 04 / 14$ & $09 / 0516$ \\
\hline AGC-5 Design and Fabrication & $10 / 01 / 12$ & $11 / 18 / 13$ \\
\hline AGC-5 Irradiation & $12 / 10 / 13$ & $11 / 30 / 16$ \\
\hline AGC-5 PIE & $01 / 05 / 16$ & $06 / 11 / 18$ \\
\hline AGC-6 Design and Fabrication & $03 / 03 / 14$ & $05 / 04 / 15$ \\
\hline ATR CIC & $02 / 02 / 15$ & $08 / 31 / 15$ \\
\hline AGC-6 Irradiation & $12 / 06 / 16$ & $10 / 08 / 18$ \\
\hline AGC-6 PIE & $01 / 01 / 19$ & $07 / 05 / 21$ \\
\hline HTV-1 and 2 Design and Fabrication & $10 / 01 / 10$ & $04 / 30 / 12$ \\
\hline HTV-1 and 2 Irradiation & $05 / 01 / 12$ & $10 / 29 / 12$ \\
\hline HTV-1 and 2 PIE & $10 / 31 / 12$ & $04 / 06 / 15$ \\
\hline ASME CDE CASE DEVELOPMENT & $11 / 02 / 09$ & $07 / 31 / 21$ \\
\hline ASME CODE CASE REVIEW/APPROVAL & $12 / 01 / 15$ & $07 / 30 / 21$ \\
\hline & & \\
\hline
\end{tabular}

Figure 11. Graphite data and qualification program schedule. 


\section{HIGH TEMPERATURE MATERIALS QUALIFICATION}

The high outlet temperature of an HTGR, above $750^{\circ} \mathrm{C}$ depending on the application need, requires the development of high-performance metallic alloys to transfer heat from the reactor to the process application. Because these alloys will contain the high-pressure helium used to cool the reactor, stringent requirements are imposed to ensure that this piping and the equipment through which the helium flows, called the pressure boundary, will maintain its integrity. Design of the pressure boundary and the materials used in these applications must meet the requirements of the nuclear section of the ASME Code. Currently, high temperature alloys and associated ASME codes for reactor applications are approved only up to $760^{\circ} \mathrm{C}$. Thus, the goal of high temperature materials $\mathrm{R} \& \mathrm{D}$ is to obtain the performance data required to support the development of these high temperature components and associated design codes over the broader range of envisioned outlet temperatures for HTGRs to support co-generation of steam and electricity at lower temperatures $\left(750-800^{\circ} \mathrm{C}\right)$ and hydrogen production and hot gas delivery at higher temperatures $\left(850-950^{\circ} \mathrm{C}\right)$ for a variety of end user applications. ${ }^{11,12}$

\subsection{Metallic Options}

A number of solid-solution-strengthened, nickel-based alloys have been considered for application in heat exchangers and core internals for an HTGR. The primary candidates are Inconel 617, Haynes 230, Incoloy $800 \mathrm{H}$, and Hastelloy X. Of these alloys, only Incoloy $800 \mathrm{H}$ is currently approved for high temperature design in the ASME Code and only up to $760^{\circ} \mathrm{C}$. As the outlet temperature increases from 750 to $950^{\circ} \mathrm{C}$, the number of potential alloys decreases and the specific material issues change. Based on the technical maturity, availability in required product forms, experience base, and mechanical properties at elevated temperatures, all of the NGNP preconceptual design studies have specified Alloy 617 as the material of choice for heat exchangers. A draft ASME code case for Alloy 617 was also developed in the past. Although action was suspended before ASME accepted the code case, this draft code case provides a significant head start for achieving material codification. Similarly, Alloy $800 \mathrm{H}$, which is already listed in the nuclear section of the ASME code, is the material of choice for control rod sleeves, although the maximum use temperature and time need to be increased. For steam generations, Alloy $800 \mathrm{H}$ is the preferred alloy because of experience with previous ATGR steam generators and because of its Code status. Alloy $800 \mathrm{H}$ and Hasteloy X are potential options for internal core metallics (e.g., core barrel, core support structure).

\subsection{High Temperature Materials R\&D}

The objective of the high temperature materials R\&D program is to establish the relevant thermo-mechanical performance data to support the development of the high temperature components operating between 750 to $900^{\circ} \mathrm{C}$. Creep, creep-fatigue, aging, and environmental degradation testing is planned using the candidate high-temperature alloys such as Incoloy $800 \mathrm{H}$ and Inconel 617 (see Figure 12). Constitutive models are also needed to describe the behavior of the alloy in tensile loading at elevated temperatures. Thick and thin sections of base material, weldments, and other joints such as diffusion bonding will be evaluated given the different design options under consideration for the intermediate heat exchanger (IHX). Depending on the outlet temperature, additional high temperature data may be needed to support relevant ASME code cases for the material.

Additional scoping studies of potential degradation of the properties of material candidates are required to characterize the high temperature interaction with the anticipated HTGR helium environment. Phenomenological models for environmental degradation and greater understanding of the kinetics of degradation are needed to help bound the requirements for control of impurities in the primary and secondary helium during operation of the HTGR. Tests are specified to determine environmental effects on microstructure and properties. 
The availability of large components, ease of fabrication, and nuclear service experience with the A508/533 steels strongly favor their use in the reactor pressure vessel for the NGNP, a near-term application of an HTGR. This material selection reduces the amount of R\&D needed. The majority of additional information that is required is related to long-term aging behavior at HTGR vessel temperatures, which are higher than those commonly encountered in the existing database from light water reactor (LWR) experience in the anticipated HTGR environment.

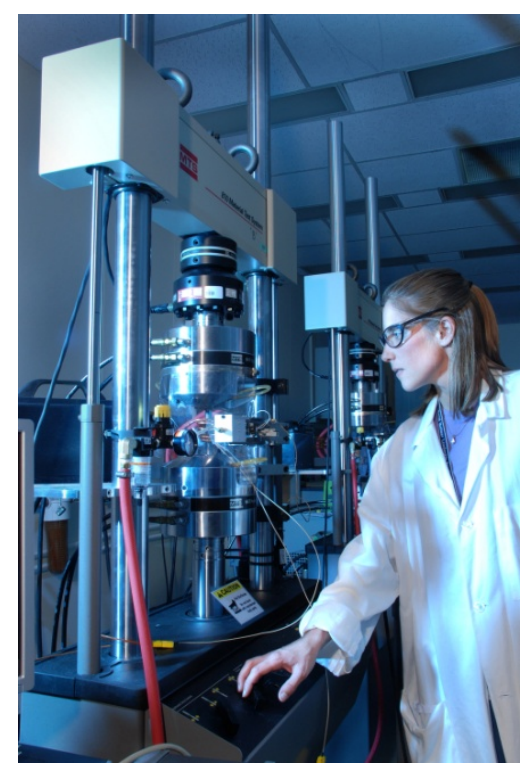

(a)

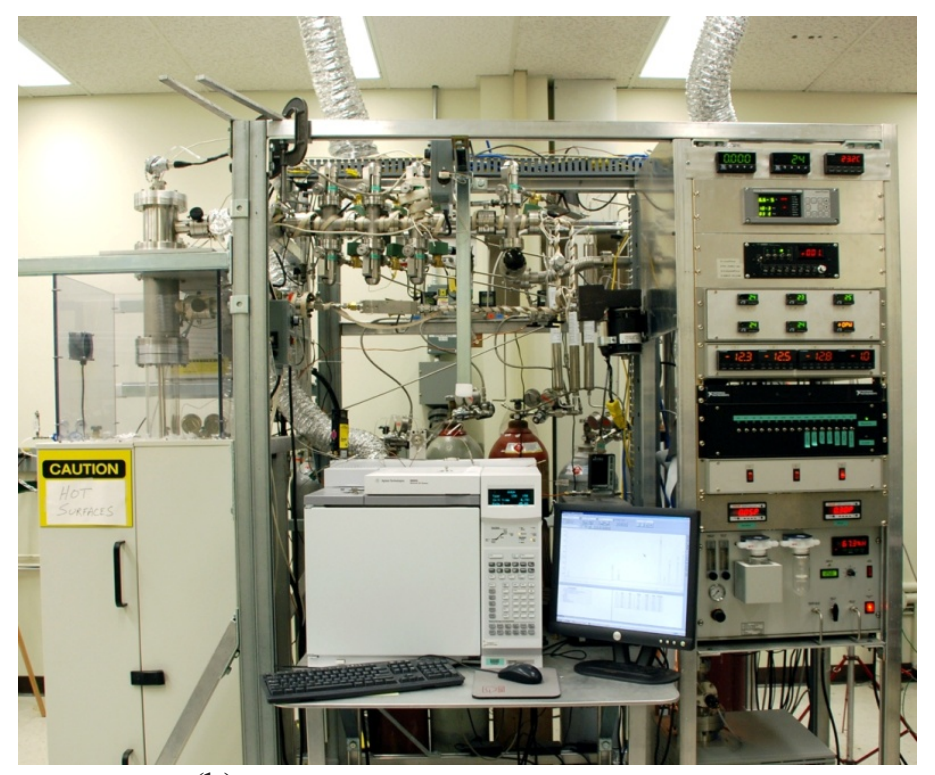

(b)

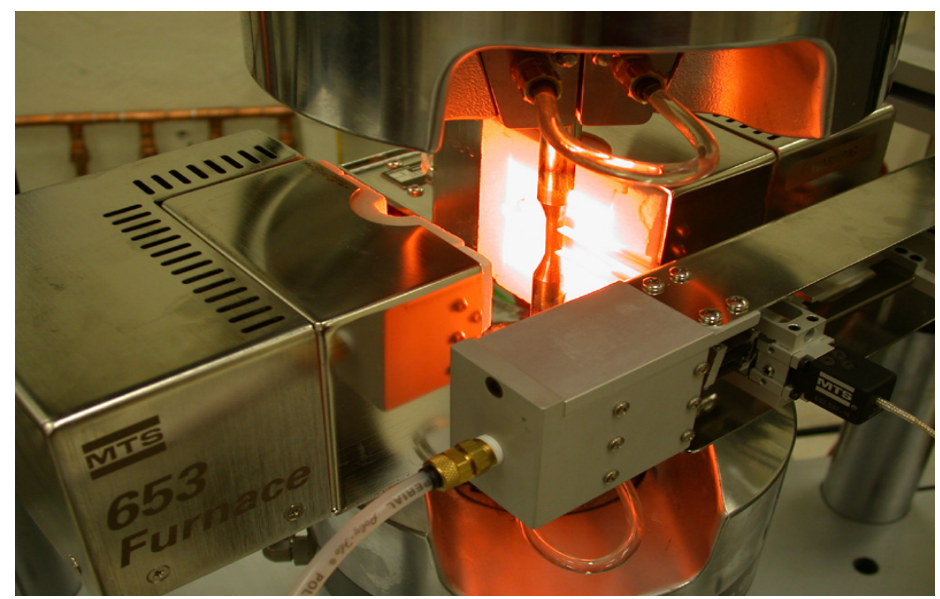

(c)

Figure 12. Examples of high temperature material testing (a) Creep fatigue testing, (b) Controlled helium impurity test loop, (c) Creep-fatigue specimen at $1,000^{\circ} \mathrm{C}$.

The R\&D required to establish requisite in-service inspection (ISI) techniques will be developed as key components are designed. Prototype testing of key components is envisioned in a high temperature flow loop to characterize overall behavior under prototypic HTGR flow conditions and to validate ISI techniques. 
Production-grade quantities of candidate high temperature alloys have been procured. State-of-the-art mechanical and environmental testing of the candidate high temperature metallic alloy is underway to understand its mechanical behavior at high temperatures and ensure that it does not degrade after long-term exposure to low levels of moisture and other impurities in the helium coolant environment at the high temperatures expected in an HTGR. Extensive development of the testing equipment and its associated experimental procedures was required to modify traditional material test systems to accommodate the high temperatures necessary to obtain the accuracy and repeatability needed to qualify the alloys for use in a nuclear system like those found in HTGRs. The testing will cover a broad range of anticipated physical dimensions and structures to be used for the high temperature components, including both thick and thin sections of the alloy, flat plate and tubes, as well as welded sections and other joints to ensure adequate structural performance and safety margins for use in the HTGRs. A detailed characterization of each alloy is performed after each test to understand the underlying behavior at the microscopic scale that contributes to the measured mechanical behavior of the metal. All of the high temperature performance data generated in the testing will be needed for ASME to certify the structural adequacy of the high temperature metals via an established process, a part of the NGNP licensing process. As the design of the high temperature components in NGNP matures, R\&D is envisioned to establish techniques to inspect the metals that form the pressure boundary during operation of the reactor. Integrated testing of key high temperature components, or testing them with the connections and in the environment experienced as part of HTGR, will be needed to characterize the integrated behavior and validate the inspection techniques for use in NGNP. An acquisition strategy for the large components was established. ${ }^{13,14}$ Major alloy grades and the availability of large components were assessed and it has been determined that there will be few issues associated with required product forms of the alloys under study. A detailed discussion of materials was recently provided to the NRC in a white paper. ${ }^{10}$

Recent testing on the creep behavior of Alloy 617 indicates that the majority of the alloy's life will be spent in tertiary creep regime, not in primary and secondary creep (see Figure 13). ASME design rules written for typical stainless-steel behavior must be modified to account for the behaviors in Alloy 617, or unrealistic lifetime predictions will severely limit design life. Creep-fatigue of base metal and weldments is the degradation mechanism of primary concern. Currently, mechanical testing experiments are focusing on determining the effect of tensile hold time on cycles to failure and properly summing combined effects of creep and fatigue for lifetime prediction.

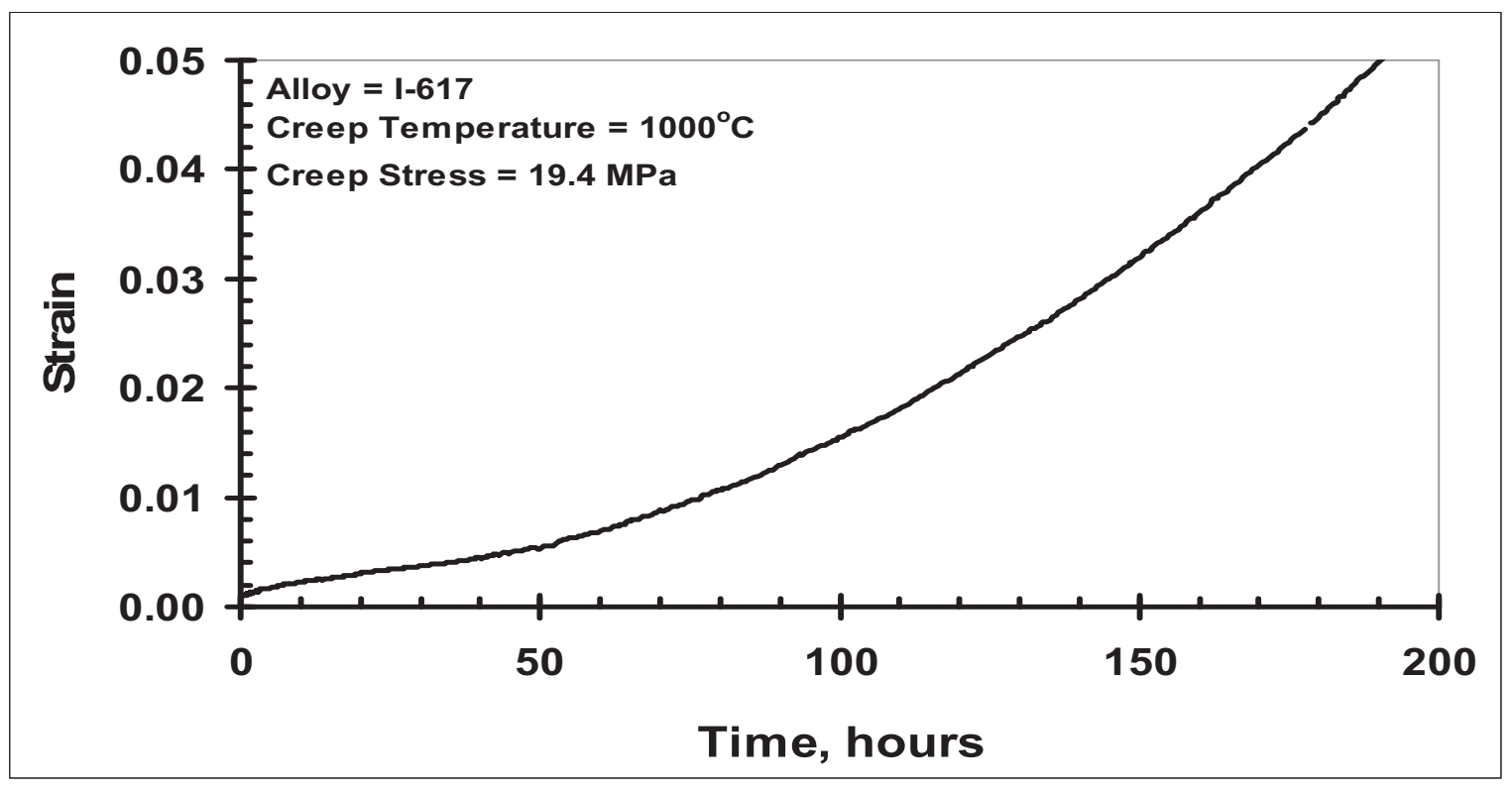

Figure 13. Mechanical response of Alloy 617 indicating tertiary creep. 
A low-velocity flow loop has been developed to evaluate the effects of the low level of impurities in He on Ni-based alloys. As expected, NGNP He chemistry is not inert with respect to Ni-based alloys. Testing is focusing on determining an acceptable range of operating chemistry for the primary helium coolant. The results indicated that a slightly oxidizing chemistry results in maximum component life.

A detailed resource-loaded activity-based schedule for the activities presented in the technical program plans for high temperature materials has been developed and is used to guide and prioritize activities year by year. A higher-level summary of that schedule is shown in Figure 14. The long duration of the activities is associated with long term creep testing of key alloys for the proposed 60-year lifetime of the materials. Based on the schedule, codification of the materials to be used by NGNP is anticipated to be qualified by 2017 assuming the funding levels required to accomplish the tasks is made available.

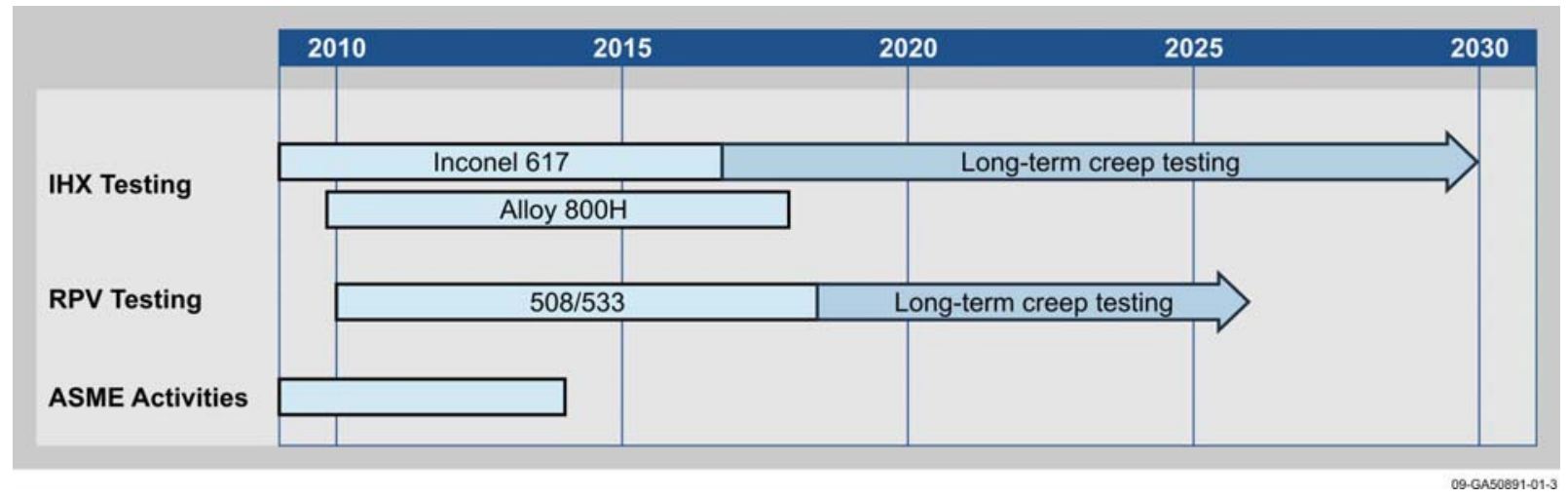

Figure 14. High temperature materials schedule. 


\section{DESIGN AND SAFETY METHODS DEVELOPMENT AND VALIDATION}

\subsection{Background and Objectives}

The methods R\&D area focuses on the development and validation of tools to assess the neutronic and thermal fluid behavior of the plant. An important activity in designing and licensing an HTGR is to confirm that the intended HTGR analysis tools can be used confidently to make technical decisions, ensure that all reactor systems are safe, and meet the performance objectives of the design. The R\&D activities defined in the design methods development and validation program ${ }^{15}$ will ensure that the tools used to perform the required calculations and analyses are validated and can be trusted. The methods $R \& D$ tasks are designed to ensure that the calculational envelope of the tools used to analyze HTGR reactor systems fully encompasses the operational and transient envelope of the HTGR. Thus the primary objectives of the Design and Safety Methods Development and Validation R\&D is to:

1. Define the calculational envelope required to be able to analyze the candidate HTGR reactor systems.

2. Define and develop an NGNP Evaluation Model that should be capable of performing all the required calculations encompassed by the calculational envelope developed in item 1 . This Evaluation Model shall provide reference results against which licensee and regulator simulation results can be compared.

3. Design and execute a matrix of experiments that will produce a comprehensive data set that can be used to enable a comprehensive verification and validation (V\&V) of the NGNP Evaluation Models developed by DOE, the NRC, and the vendors..

4. Support near-term deployment of the NGNP for process heat and electricity production in the U.S. (2021) by reducing market entry risks posed by technical uncertainties associated with thermal fluid and neutronic phenomena

5. Develop an uncertainty and sensitivity analysis capability that can be used to identify and prioritize gaps in the ability of an Evaluation Model to compute safety and performance parameters within confidence intervals.

6. Utilize international collaboration mechanisms to extend the value of DOE resources (e.g., GIF very high temperature reactor [VHTR] activities).

To date, since the NGNP design has not formally been selected, the Design and Safety Methods Development and Validation R\&D effort has focused on primary objectives 1, 2, and 3. However, all the work performed to date will have to be evaluated, upon selection of the NGNP design, to confirm the degree to which it is applicable to the design of choice.

As a starting point, DOE researchers have participated with colleagues at the NRC using a well-established expert solicitation process to establish a ranking of important events that might occur during accidents in HTGRs. An optimal allocation of resources for safety-related R\&D activities was developed based on the importance of the specific accident-related event to the overall safety of HTGRs and the associated level of technical knowledge. Areas where the importance is high and the knowledge is low receive the greatest attention. Areas of focus include (a) assessing, benchmarking, and improving reactor physics and kinetic methods and data for prismatic and pebble-bed HTGRs, (b) evaluating important phenomena that influence thermal-fluid behavior in HTGRs and establishing relevant separate effects and scaled integral experiments for verification and validation, (c) developing experiments to validate reactor cavity cooling system behavior, and (d) evaluating and establishing system-level codes appropriate for HTGR safety. The normal and off-normal scenarios and the associated physical phenomena that the reactor simulation programs can calculate with confidence define the calculational 
envelope of software and data used for HTGR designs. The software tools can only be used confidently once the results they produce have been shown to be in reasonable agreement with first-principle results, analytic solutions, and data. The NRC expects it is expected by the NRC that the scope of these results, solutions and data describe completely the highly ranked phenomena inherent in all operational conditions and important accident scenarios for the HTGR.
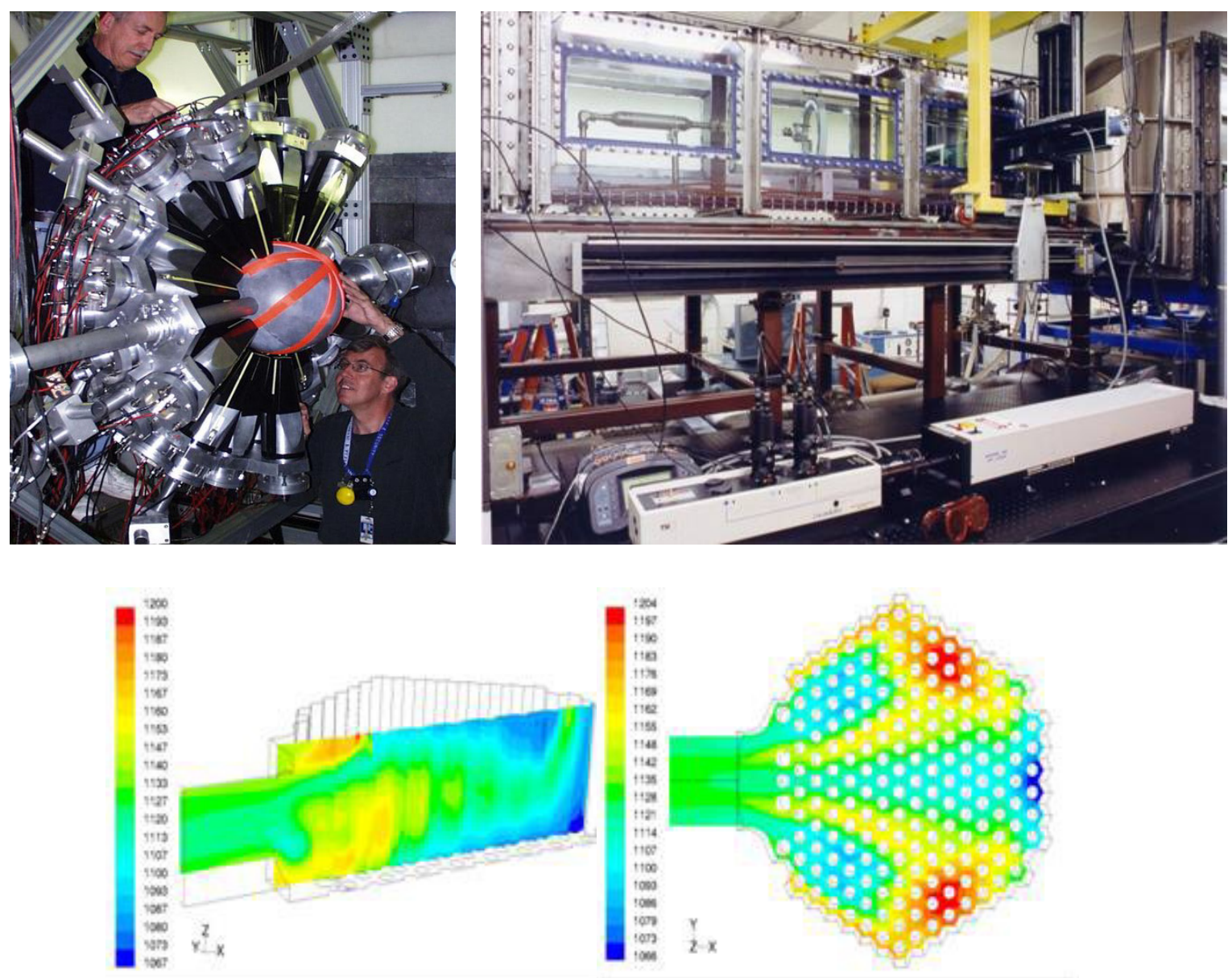

Figure 15. Experiments and computer simulations used in HTGR design and safety.

The tools available for the design and analysis high temperature reactors have not been updated with the new methods and computational advances to which LWR analysis tools have been subjected. The approximate methods employed in these legacy HTR tools give rise to considerable uncertainties in the prediction of key safety parameters ${ }^{16}$ such as peak temperature and shutdown worth. Considerable development and validation of new and existing physics and thermal fluid analysis tools has begun. Accepted. The practices and procedures are being defined and implemented based on NRC regulatory guides for code validation.. Computational fluid dynamics (CFD) software, which has never been used in large measure to perform auditing, design, or licensing calculations for a nuclear plant, is anticipated to be widely used to analyze the HTGR behavior. Although plant analysis software has been validated for specific cases, data must be generated for the wider range of HTGR phenomena that are anticipated for normal and off-normal operation.

In addition, the NRC is establishing their set of analytic tools with which to perform confirmatory assessments of vendor calculations submitted as part of the NGNP combined license (COL). Cross comparisons between this suite of tools (vendor tools, NRC code suite, and DOE software) and 
comparisons to the large-scaled integral experiments are critical to improving design capabilities and confidence in all of the analytical tools and support licensing.

\subsection{Overview of R\&D}

A series of benchmarks of core simulation tools is underway for both pebble-bed and prismatic reactors. The benchmarks consist of tools under development by the NRC, those under development for the DOE as part of the NGNP project, and vendor tools. Table 2 describes the benchmarks and facilities in the program.

Table 2. Benchmarks and facilities suitable for NGNP code validation and verification.

\begin{tabular}{|c|c|c|}
\hline Type of Benchmark & Physics Captured & Examples \\
\hline Critical Facility & $\begin{array}{l}\text { Flux profiles, global reaction rates, } k_{\text {eff, }} \text {, rod worth, } \\
\text { isothermal temperature coefficients }\end{array}$ & $\begin{array}{l}\text { ASTRA, PROTEUS, Very High } \\
\text { Temperature Reactor (VHTR)-C }\end{array}$ \\
\hline Engineering/Test Reactor & $\begin{array}{l}\text { Flux profiles, global reaction rates, } k_{\text {eff, }} \text {, rod worth, } \\
\text { reactivity coefficients, power profiles, coarse } \\
\text { temperature maps, global transient behavior, passive } \\
\text { and active system dynamics, fission-product } \\
\text { transport }\end{array}$ & $\begin{array}{l}\text { High Temperature Reactor (HTR)-10 } \\
\text { High Temperature Test Reactor } \\
\text { (HTTR) International Reactor } \\
\text { Physics Experiment Evaluation } \\
\text { Project (IRPhEP) }\end{array}$ \\
\hline $\begin{array}{l}\text { Pin/Pebble or Block/Pebble } \\
\text { Box Standard Problems }\end{array}$ & $\begin{array}{l}\text { Neutron scattering and absorption (heterogeneity, } \\
\text { resonance effects, self-shielding), depletion }\end{array}$ & $\begin{array}{l}\text { Simplified HTTR Block Model } \\
\text { CRP-5 Pebble Box, HTGR Depletion } \\
\text { Benchmark (ORNL) }\end{array}$ \\
\hline $\begin{array}{l}\text { 2D Isothermal Sub-core } \\
\text { Standard Problem }\end{array}$ & Spectral coupling (R-q), flux profiles, local absorbers & $\begin{array}{l}\text { HTTR } 1 / 12^{\text {th }}, \text { or } 1 / 6^{\text {th }} \text { core axial } \\
\text { planes }\end{array}$ \\
\hline $\begin{array}{l}\text { 3D Partial or Full Core } \\
\text { Steady State Standard } \\
\text { Problem }\end{array}$ & $\begin{array}{l}\text { Spectral coupling (axial and radial), flux profiles, rod } \\
\text { worth, and isothermal temperature coefficient } \\
\text { predictions }\end{array}$ & $\begin{array}{l}\text { HTTR and HTR-10 initial criticality } \\
\text { (CRP-5), } \\
\text { General Atomics-Modular High } \\
\text { Temperature Gas cooled Reactor } \\
\text { (GA-MHTGR) Neutronics } \\
\text { Benchmark }\end{array}$ \\
\hline $\begin{array}{l}\text { R-Z or 3D Core with } \\
\text { Specified Boundary } \\
\text { Conditions } \\
\text { - } \quad \text { Fixed temperature map } \\
\text { - } \quad \text { Fixed power map } \\
\text { - } \quad \text { Fixed inlet coolant } \\
\quad \text { conditions }\end{array}$ & $\begin{array}{l}\text { Core transient response predictions } \\
\text { - } \quad \text { Predicted power and flux profiles } \\
\text { - } \quad \text { Thermal fluid maps (pressure, flow, temperature) } \\
\text { - } \quad \text { Predicted criticality condition, hot steady state } \\
\text { - } \quad \text { Wide-range transient response }\end{array}$ & $\begin{array}{l}\text { PBMR } 400 \text { Coupled Core Transient } \\
\text { Benchmark, Proposed Block CCTB, } \\
\text { HTTR and HTR-10 start-up core } \\
\text { (CRP-5) }\end{array}$ \\
\hline $\begin{array}{l}\text { Integral Core Thermal Fluid } \\
\text { Test Facility }\end{array}$ & $\begin{array}{l}\text { Core Thermal Fluid behavior during and after a pipe } \\
\text { break } \\
\text { - Steady state core heat transfer characteristics } \\
\text { - Temperature profiles during a loss of forced } \\
\text { Cooling } \\
\text { - Air ingress rates and characteristics } \\
\text { - Natural Circulation behavior under loss of forced } \\
\text { cooling }\end{array}$ & $\begin{array}{l}\text { High Temperature Test Facility and } \\
\text { associated separate effects } \\
\text { experiments } \\
\text { High Temperature Test Facility } \\
\text { (South Africa) } \\
\text { High Pressure Test Facility (South } \\
\text { Africa) } \\
\text { Helium Test Facility (South Africa) }\end{array}$ \\
\hline $\begin{array}{l}\text { Ex-core Heat Transfer } \\
\text { (RCCS) Facility }\end{array}$ & $\begin{array}{l}\text { Vessel Heat rejection rates and dependencies } \\
\text { - natural circulation flow patterns between the vessel } \\
\text { and RCCS risers } \\
\text { - effect of dust on heat rejection } \\
\text { - water and air0cooled RCCS performance } \\
\text { parameters }\end{array}$ & $\begin{array}{l}\text { Natural Circulation Shutdown test } \\
\text { Facility and associated separate } \\
\text { effects experiments and }\end{array}$ \\
\hline CFD Benchmarks & $\begin{array}{l}\text { Fundamental fluid behavior in simple geometries and } \\
\text { conditions }\end{array}$ & ASME Standard Problems \\
\hline
\end{tabular}




\begin{tabular}{lll} 
Type of Benchmark & Physics Captured & Examples \\
\hline & - flow patterns and temperature profiles around core & \\
& structures & \\
& - flow patterns, temperature profiles, and sensitivities \\
& between blocks \\
& - Natural circulation profiles inside the core
\end{tabular}

The NGNP core simulation team has made considerable progress in the construction of an Evaluation Model. Simulation of pebble bed reactor fuel cycles has been demonstrated using the PEBBED code developed at the INL. A PEBBED simulation involves a complex coupling of neutronics, fuel shuffling and burnup, spectrum analysis, and thermal fluid modules that yield steady state core profiles (power, temperature, isotopics) for a recirculating pebble bed reactor. A complementary transient solver for PBRs has been demonstrated in two dimensions with the CYNOD code, which has been coupled to the RELAP system analysis code for simulating PBR plant dynamics. CYNOD has also been coupled to the legacy thermal fluids code THERMIX code for simulating the core transients in the PBMR400 Transient Benchmark. A comparison of simulations performed analysts around the world reveal considerable disparity in the prediction of the response of an HTGR core to the withdrawal of a control rod (Figure 16)

THERMIX was further modified to generate precise, time-dependent values of the kernel temperature during earthquake-induced reactivity transients (compaction of the pebble bed). Development of an accurate neutronic treatment of the control rods in the PBR reflector is almost complete but a proper 3D thermal fluid solver must be added so that rod withdrawal transients can be simulated.

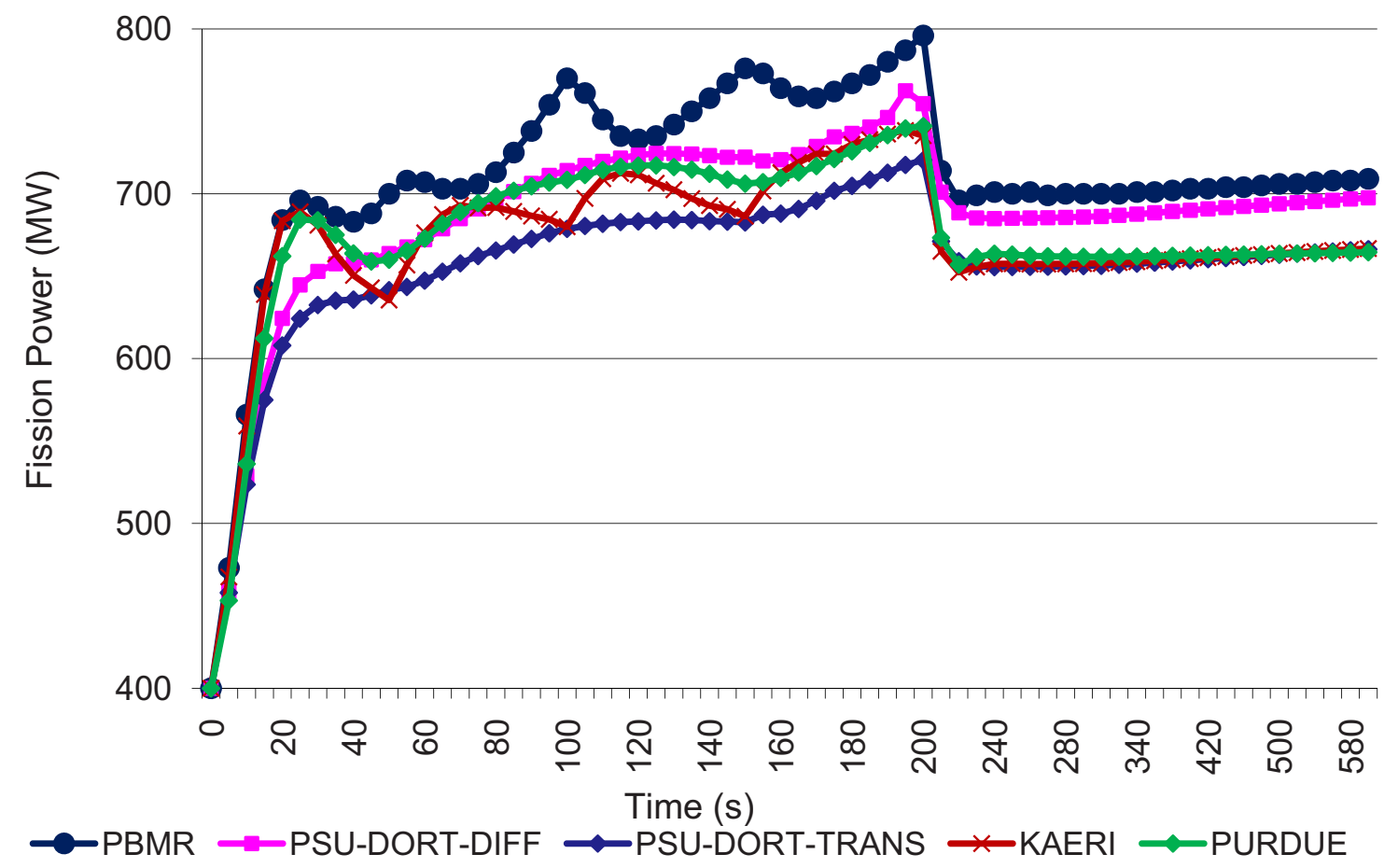

Figure 16. Multiple predictions of core power response to the withdrawal of control rods in the PBMR $400{ }^{17}$

A new nodal diffusion solver for prismatic VHTRs has been developed and demonstrated. It uses a analytical Nodal Green's Function method that was demonstrated to achieve higher accuracy than the polynomial expansion method used in existing HTGR codes. This code was also modified to treat 
burnable poisons in the fuel blocks. The reactivity and power peaking effect of these absorbers is not treated properly by existing prismatic neutronic codes. A transient version of the new code is being tested but complimentary burnup and fuel shuffling modules have yet to be developed. Likewise the development of a thermal fluid solver for providing temperature feedback in transient calculations is an outstanding goal.

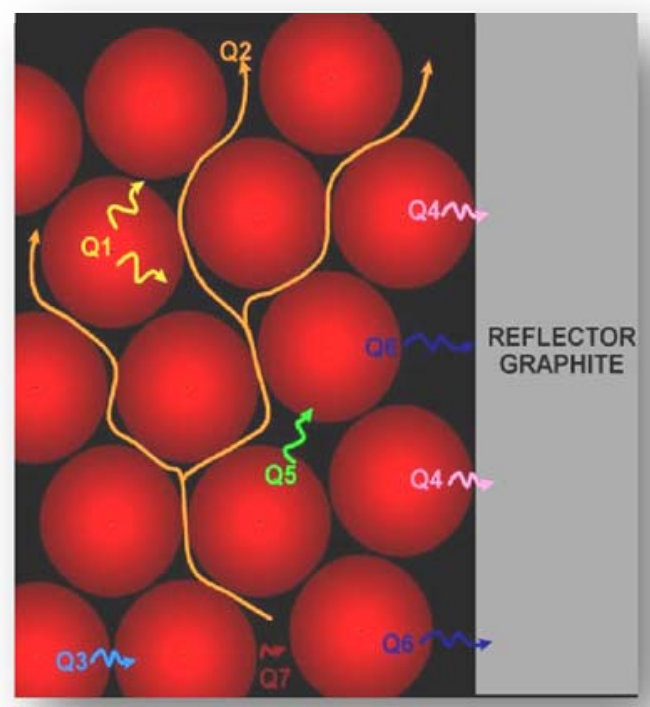

Figure 17. Fluid and Heat Transport near the core-reflector boundary of a pebble bed reactor

High fidelity multiphysics calculations that run on massively parallel computers are just becoming practical for reactor applications. The NGNP Core Simulation team is investigating the use of a new multiphysics simulation tool (PRONGHORN) for investigating complex, safety-significant phenomena just as heat generation and transfer at the corereflector boundary in a pebble bed (Figure 16). Legacy analysis tools are known to be deficient in treating the complex interactions of neutron, coolant, and heat transport in this region. The effect of radiation on the graphite block shape and the flow of coolant between the blocks can also be studied with these tools. Such simulations will increase understanding of the complex material interactions and will help to quantify uncertainties in design calculations.

All of the codes (developmental or commercial) used for NGNP design and analysis must be subjected to rigorous qualification process before they can be used for a license application. NGNP Methods R\&D staff are working with the NRC to jointly develop and execute a set of large-scale experiments to provide safety-related data that will be used independently by reactor designers and the NRC to validate modeling and simulation tools used to design a reactor or assess the safety of the design. This joint development effort avoids duplication of costly experiments by DOE and the regulator. As shown in Table 2, the two major experiments being constructed today are (1) the High Temperature Test Facility (HTTF), an integral invessel experiment at Oregon State University, and (2) a simulation of the reactor cavity cooling system, the heat sink for the HTGR, at Argonne National Laboratory (ANL) (see Figure 18).

Scaling studies are underway to properly define the experiments to be used in these facilities. A larger number of separate effects tests are also planned or underway in universities to support these larger integral test facilities. Figure 16 shows an experiment designed to simulate the flow of hot helium gas around the structures in the lower plenum of the HTGR along with a corresponding computer simulation of that flow.

Other experimental work performed thus far includes a study of two-component exchange flow that simulates the replacement of helium in the pressure vessel with air after a pipebreak. The flow of helium around prismatic reactor fuel blocks (bypass flow) has also been investigated experimentally in Korea through a collaboration with Seoul National University.

The DOE and NRC have also initiated a joint collaboration with the Japanese gas reactor team to obtain unique operational data from their operating high temperature gas test reactor (the HTTR) to validate modeling and simulation tools that predict the behavior of the integrated reactor system. Assessments are currently underway by DOE, NRC, and laboratory personnel to technically evaluate other international capabilities that can be used to provide relevant safety data (e.g., HTR-10 the 10-MW pebble bed in China, the SANA heat transfer and NACOK, integral air ingress facilities in Germany). 

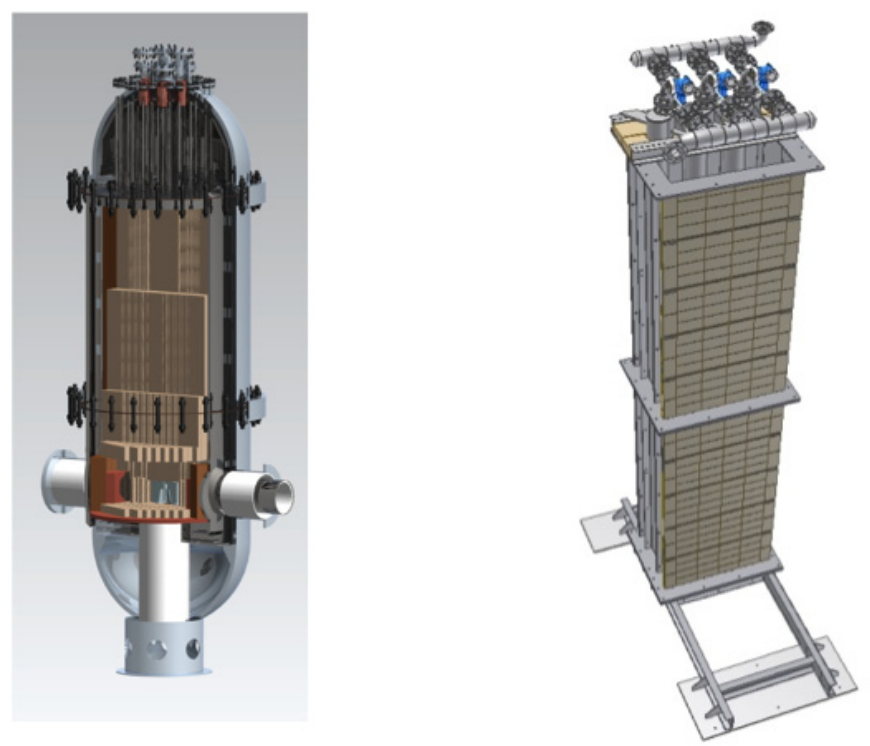

Figure 18. Schematics of the HTTF at Oregon State University and the reactor cavity cool-down system (RCCS) simulation at ANL.

A high-level methods schedule is shown in Figure 19. Methods R\&D will focus on applying, improving, and/or developing the tools necessary to predict the behavior of the candidate HTGR designs via separate effects testing, benchmarking, and developmental assessment. In the longer term, software tools will be validated using data from large-scaled integral experiments.

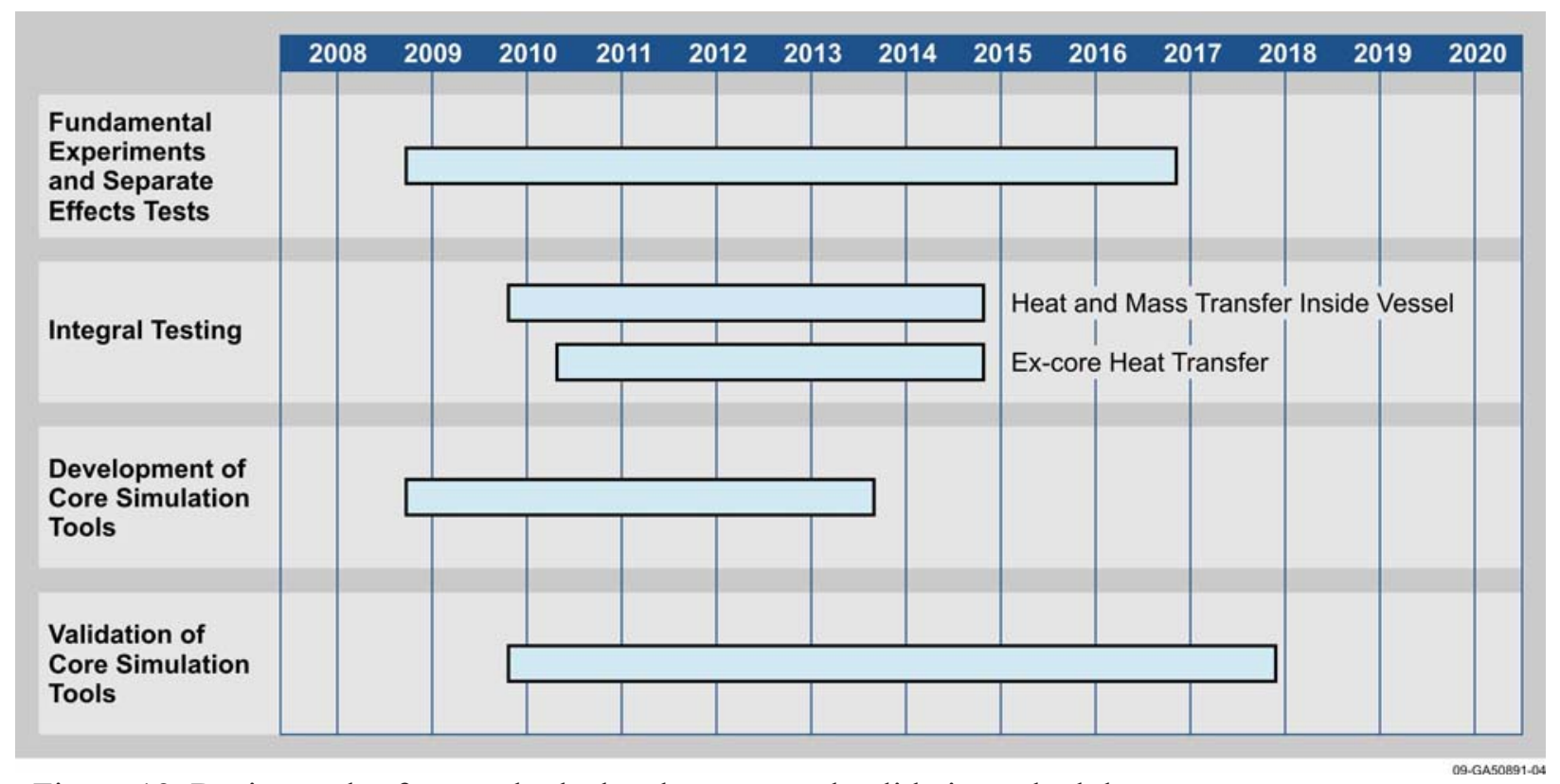

Figure 19. Design and safety methods development and validation schedule. 


\section{HEAT TRANSPORT AND SYSTEM INTEGRATION}

Economic substitution of reactors for fossil fuels in conventional processes requires integrated, efficient heat-transport systems to exploit all of the reactor's heat. The purpose of this effort is to analyze potential processes when coupled to a gas cooled reactor, based on technical merit, emissions reductions, and economic parameters such as product costs, energy security, and job creation. Development and demonstration of the components and systems needed to deploy the most promising processes will be complete when they progress to the technical maturity needed to predict successful deployment at commercial scale. Predicting successful commercial deployment can be achieved by meeting the major objectives in heat transport and system integration, which are:

- Establish and model baseline heat transport and process configurations for applications with high potential for economical emissions reductions and efficient use of fossil fuels

- Optimize the most promising integrated heat transport and process configurations; identify technology development needs to implement baseline configurations and for process improvements

- Perform technology development studies that span the gap between fundamental research and technology demonstrations, including cross-cutting issues such as evaluation of thermal transients to and from the reactor and the process and tritium permeation through the heat-transfer surfaces in the system

- Create the component and pilot-scale testing infrastructure necessary for technology development and for demonstration and validation of key components and integrated systems including monitoring and control strategies

- Develop and validate modeling tools for components, systems, and cross-cutting issues that impact coupling chemical and nuclear processes through component and pilot-scale testing.

The following tasks must be completed for the heat transport and system integration program to meet these objectives:

- Establish and model heat transport and process configurations. Understanding industrial applications and available heat-transport systems is necessary to establish a baseline to start from. Dynamic systems modeling can define nuclear-industry interfaces, incorporating heat, electricity and/or hydrogen production required to substitute nuclear heat for conventional energy sources. Further, dynamic systems modeling will characterize local and regional impacts from and on land resources, as well as air and water quality. By understanding all of the process requirements, efficient use of all of the reactor heat, including heat traditionally categorized as waste heat, can be achieved.

- Develop and use, as required by this activity, detailed process models using commercial software that accurately represents heat integration, material balances, and capital and operating costs. The models must be detailed enough to develop product costs based on (1) available or close-to-market technologies, (2) current equipment and commodity costs, and (3) economic factors such as internal rates of return, credit costs, and potential emission taxes. By developing models and establishing an "art of the possible" baseline, selection of the most promising applications can focus subsequent optimization and prioritization activities.

- Optimize heat transport and process configurations and identify technology development needs. The most promising integrated models should be optimized for impact to cost, emissions, resource conservation, and energy independence. Economic evaluations should consider the needs of industry partners, as the business model needed to deploy a specific application may vary considerably. Evaluation of emissions, resource conservation, and energy independence should consider factors such as spent fuel storage costs, infrastructure modifications, market penetration, job creation, and time-dependent impact on national and international emission reduction goals. 
- Base technology development needs on deployment of the optimized flowsheets to maximize the benefit of the investment. Technology development can be categorized as close-to-market demonstrations needed to deploy baseline technologies, broad-based needs applicable to multiple applications, and more speculative technologies that offer the most improvement over the baseline. It is anticipated that substantial industry partnering will be needed for close-to-market demonstrations, as well as some of the development of broad-based technologies. Design of bench-, experimental-, and pilot-scale experiments and facilities should be based on the technology development needs.

\subsection{Technology Development Studies}

This task explores the development of the primary components of the heat transport system. Heat transport is divided into three systems: (1) heat transfer from the reactor core to a primary heat exchanger, (2) secondary heat transport (via helium or steam as close-to-market applications and other fluids as potential process improvements), and (3) deposition of the heat in the industrial processes. Technology development efforts are needed for each system. The heat exchanger between the primary reactor coolant of an HTGR (helium) at approximately $750^{\circ} \mathrm{C}$ and the secondary heat transfer medium is a critical part of the pressure boundary for the reactor. Development and demonstration of this component is key to deployment of a first-of-a-kind HTGR. The baseline technology for heat transfer from the primary circuit is steam production at approximately $535^{\circ} \mathrm{C}$, for which technology development needs are limited and primarily focus on performance of dissimilar metallic welds. Increasing steam temperatures or hot gases used as a secondary fluid increases the complexity of new materials, fabrication methods, and components with increasing benefit for process applications in terms of thermal efficiency. Demonstration of heat exchangers benefits heat transport in all three systems.

High temperature material compatibility is a concern for all combinations of heat exchanger materials, bonding and fabrication technologies, and coolant chemistries. Developmental studies to determine optional configurations need to be performed to explore configurations of heat exchangers (see Figure 20) and the associated high temperature material options ranging from conventional (e.g., metallic shell and tube) to more advanced and innovative technologies (compact heat exchanger, ceramic heat exchanger) in conjunction with candidate transport mediums. Issues related to materials compatibility, heat transfer effectiveness, and structural robustness will be studied for the relevant application. Direct and indirect gas contact heaters need to be investigated for heat deposition. To facilitate broader application and long-distance transport of energy, longer term research is needed to extend the use of molten salts from their current applications to temperatures above $600^{\circ} \mathrm{C}$. The use of electrical power and combustion topping cycles also needs to be evaluated.
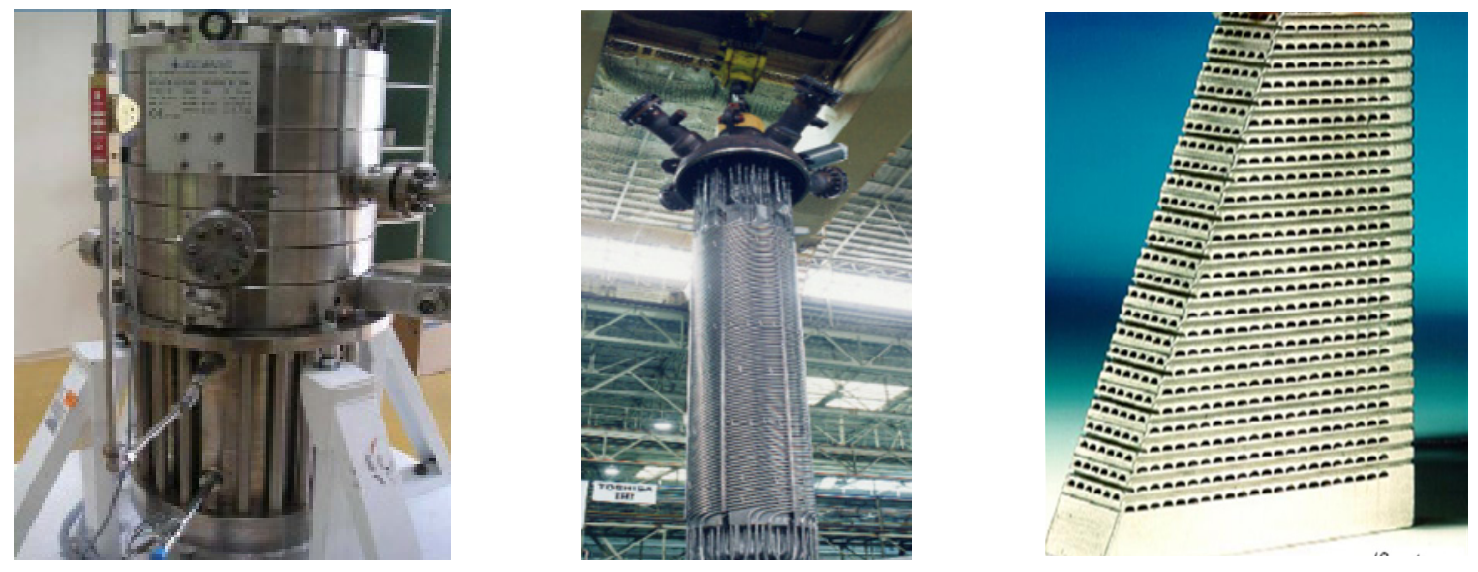

Figure 20. Examples of high temperature heat exchangers and circulators. 
Tritium permeation, thermal transients, and water management are cross-cutting issues that will affect heat-transport systems and process applications and require integration with planned R\&D. Permeation of tritium generated in the reactor primary circuit increases with an increasing temperature. While tritium is not a significant contributor to the reactor source term, its mobility creates the potential to contaminate industrial products, emissions, and discharges. The modeling, development, and demonstration of tritium removal systems are required. Because process heating is typically not a steady-state operation, transients in heat transfer and thermal inertia will need to be investigated and understood. Water management is vital to successful management of the reactor and most potential industrial applications.

Based on the results of these studies, technology development and test plans will be developed. Integrated testing will be conducted in accordance with the plans to investigate component response, component reliability, and system behavior in the relevant environment. Small-scale integral testing will validate the technology while concurrently supporting the development and demonstration of instruments and monitors for process control.

\subsection{Create Component and Pilot-scale Testing Infrastructure}

Bench-, experimental-, and pilot-scale tests are needed to evaluate single-effects and integrated system performance of new process-specific heat exchangers, components, and technologies. Such testing will validate simulation predictions and demonstrate component performance. Enabling technologies, such as demonstration of fabrication and in-service inspection techniques, can typically be demonstrated at smaller scales. Short-term and single-effects tests with faster turnarounds and multiple iterations are also performed more economically at small scales. Ongoing and planned activities include:

- Fabrication support, bench-scale development and testing that integrates the information obtained from the materials testing into component proof-of-concept demonstrations

- Static (or low flow) test rigs that provide single effects testing capability, but lower cost, at representative pressures and temperatures

- Flowing loops that provide experimental-scale demonstrations in a relevant environment.

Figure 21provides a graphical representation of the test rigs needed to mature current work on materials properties and fabrication processes to the point where an individual component is predicted to be capable of successful deployment at commercial scale. The Small Pressure Cycling Test Rig (SPECTR), Mixed Stream Test Rig (MISTER), and The Ohio State University (OSU) helium loop leverage the materials properties and fabrication development work now in progress. These test rigs are in design (SPECTR), fabrication (MISTER) or start-up testing (OSU).

Testing of fabrication methods started with scoping studies on diffusion bonding (the bonding method used for most compact heat exchangers) initiated in December 2009 using the INL Gleeble 3800 System shown in Figure 22. (The Gleeble System is a general-purpose servo-hydraulic thermo-mechanical testing device that can perform physical simulation of metallurgical processes.)

Diffusion bonding is a slow process with a relatively low applied stress that is well within the Gleeble's capacity, and the digital feedback loops are effective for precise control of the process. The Gleeble also provides a vacuum/controlled atmosphere chamber, which is required to control the surface oxidation of candidate heat exchanger alloys. Heat is provided by Joule heating of the specimen held in water-cooled grips with feedback control provided by an attached thermocouple. An image of a specimen during the diffusion bonding process in the Gleeble System is shown in Figure 22. 


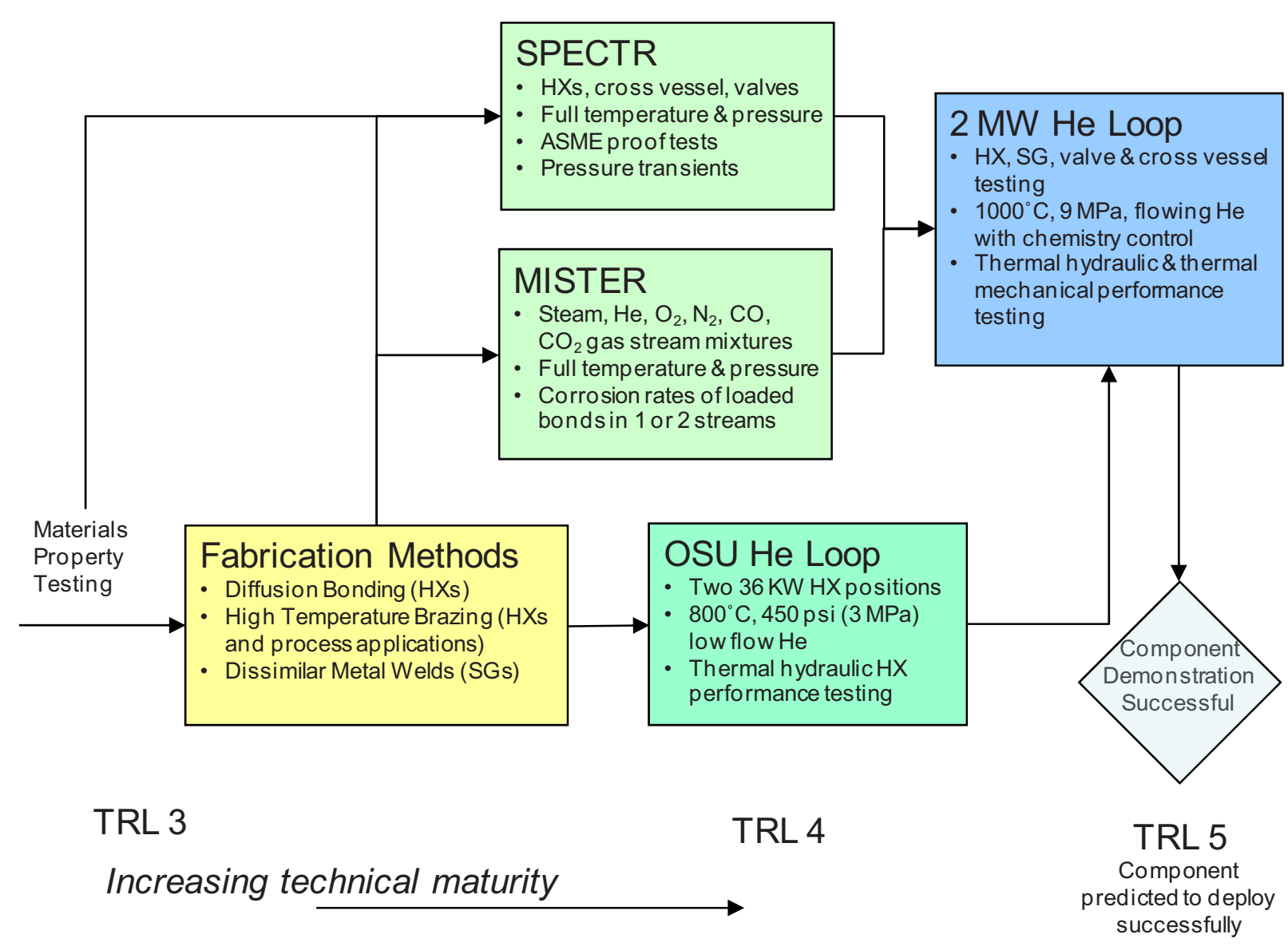

Note: SPECTR is the Small PrEssure Cycling Test Rig MISTER is the MIxed Stream TEst Rig

Figure 21. Heat Transport Component Test Capability required to mature the component technology.

The diffusion bonding process needs to be further developed and bonding process parameters and controls identified, such as mating surface pickling, nickel plating, or a nickel foil interlayer, bond temperatures, applied pressure, and hold times.

Integrated and larger component tests will be performed at larger scales and can provide system performance data and demonstration of monitoring and control systems. Long-term and integral tests are typically more complex and require more extensive instrumentation and scaling studies. Regardless of the scale or length of test, facilities will be designed for flexibility to ensure their continued value for ongoing use after the first application is tested. The first tests planned in SPECTR will be for heat exchanger unit cells fabricated with the diffusion bonding parameters developed using the Gleeble System. Corrosion data from MISTER testing and thermal hydraulic data measured with The OSU helium loop will be combined with the SPECTR data to develop test plans for integrated testing in a $2 \mathrm{MWt}$ (nominal) loop. To complete testing in relevant HTGR conditions, the $2 \mathrm{MWt}$ loop will need the capacity to test at full helium temperature and pressure in representative chemistries and scaled flow rates. This loop is expected to perform heat exchanger testing first, but also accommodate other testing of other heat transport system components. Eventually, coupled industrial processes, including hydrogen production, 
could be demonstrated with this loop. Instrumentation and controls needed for range of all potential testing should be considered in the $2 \mathrm{MWt}$ loop original design.

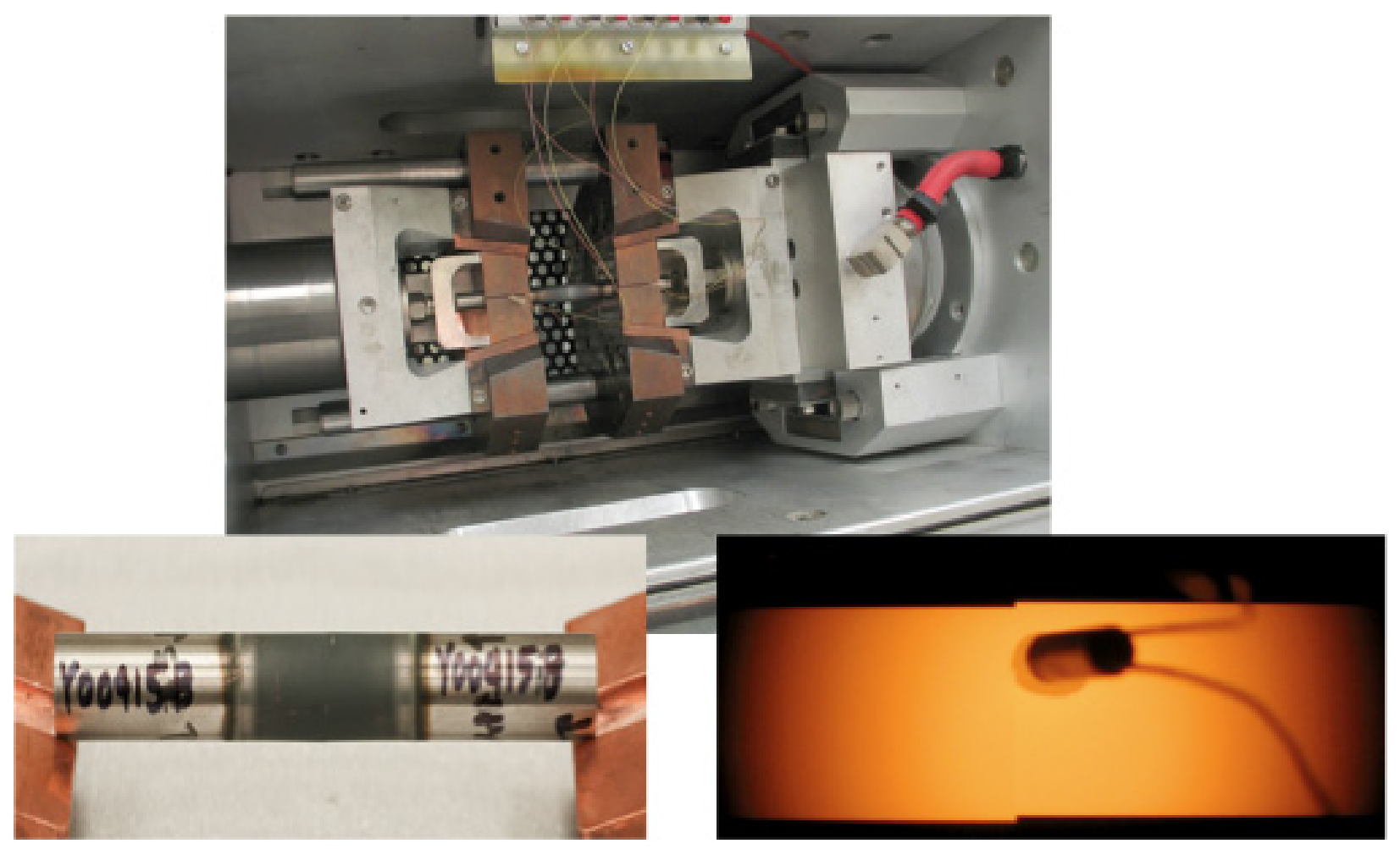

Figure 22. Diffusion bonded specimen in the Gleeble System.

Long-term testing will provide the reliability data needed to ensure that the system will meet the high availability anticipated by the end users and that it can also be performed at small scales. Integrated and larger component tests will be performed at larger pilot scales and can provide system performance data and demonstration of monitoring and control systems. Long-term and integral tests are typically more complex and require more extensive instrumentation and scaling studies. Regardless of the scale or length of test, facilities will be designed for flexibility to ensure their continued value for ongoing use after the first application is tested.

Monitoring and control development includes developing sensors/actuators, managing data, and demonstrating control systems. A hierarchical modeling and simulation framework is envisioned (see Figure 23). Each layer of the hierarchy will be informed by its parent layers and receive appropriate process data from the monitoring system. Flexibility for accommodating sensors and actuators with different levels of accuracy, precision, intelligence, and operability response would be beneficial for the integration of nuclear energy into non-electric applications. Integrated systems of smart sensors must selfassess plant conditions, regulate process variables, and relay information and knowledge pertaining to multiple unit operations. A flexible actuator capability is needed to regulate actions exerted by systems of distributed actuators. While secure data acquisition systems based on wired and field bus technologies are anticipated, wireless options may also be considered based on their intrinsic flexibility. To best meet particular information requirements and constraints, promising information architectures and infrastructures need to be investigated for efficient and secure operation. 


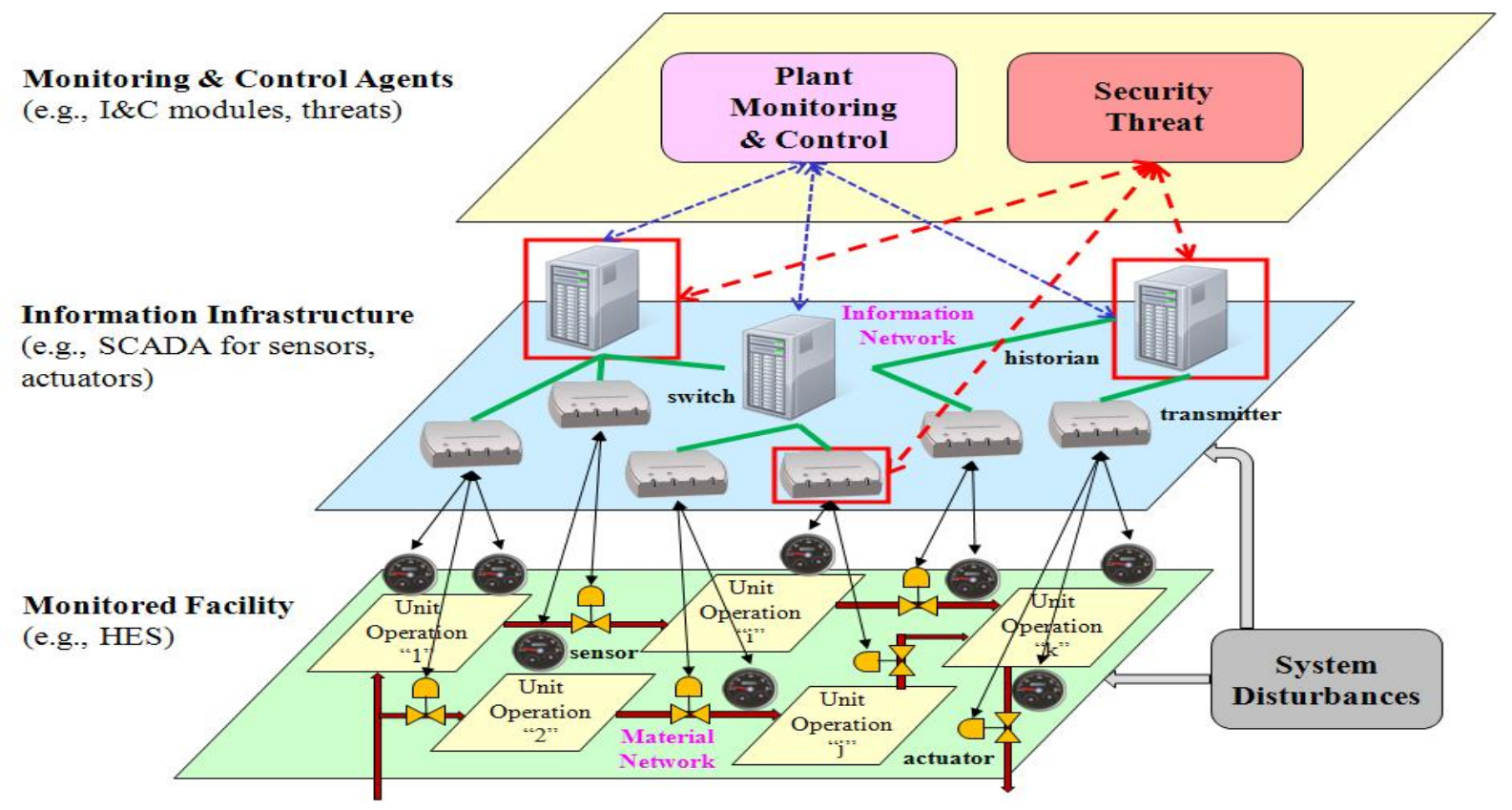

Figure 23. Levels of instrumentation and control development and integration.

Because the reactor concepts are expected to increase reactor outlet temperatures as they mature, test facilities will be designed to accommodate steady-state and operational transients for the higher outlet temperatures. It is expected that test priorities will generally consider lower temperature technologies first and schedule longer term technology development tests around the lower temperature, close-to-market tests.

Heat-transport and system integration milestones for creating testing infrastructure include:

- Complete design and fabrication of experimental scale facilities by 2012

- Complete pilot-scale demonstration, design, and construction in 2013

- Complete demonstration of pilot-scale plant heat transfer to first industrial process in 2016 (planning basis is approximately $2 \mathrm{MWt}$ transferred to a high temperature steam electrolysis model).

\subsection{Develop Modeling Tools and Validate through Testing and Demonstration}

Single-effects and pilot-scale component testing is needed to demonstrate new process-specific heat exchangers and other components needed to transport heat to the end-user application. Computer models for specific processes and heat transport components and systems ranging from the atomistic level to macro-scale have been, and will continue to be, developed. Validation of those models through testing and demonstrations is needed to deploy integrated heat-transport systems at commercial scale.

Long-term testing will provide the reliability data needed to ensure the system will meet the high availability required by the end users and in some cases required by regulatory and standards organizations. Testing is often iterative in that the results identify additional needs or opportunities. Once the test systems and experimental facilities are built and operated for the first application, the need for additional industrial applications will require their continued operation.

A high-level schedule of the heat-transport and system integration activities is shown in Figure 24. Potential processes have been identified, modeled, and independently reviewed to establish a baseline of process configurations that could be deployed with existing technologies. They are being optimized and 
evaluated to identify where technology development of components and unit operations can provide the most improvement. The economic models are being improved by adding flexibility and evaluating potential impacts on foreign oil dependence and job creation. A tritium permeation code was developed and tritium test data from the HTTR is being obtained to validate the code. A laboratory-scale test rig designed to test corrosion in the hydrogen production equipment and dissimilar metal welds is being fabricated and a test rig to evaluate small heat exchanger sections is in the design phase. A small helium loop at Ohio State University will complete start-up testing this year before conducting thermal hydraulic tests of small heat exchanger sections. Testing in all three will commence in FY2011 and build on materials properties and fabrication methods research that is already in progress. Work on experimental scale facilities - specifically, a helium loop operating at relevant temperatures and pressures with scaled flow and chemistry control- has not yet started. A life-cycle estimate and project management plan for integral pilot-scale testing of the hydrogen production process was recently completed.

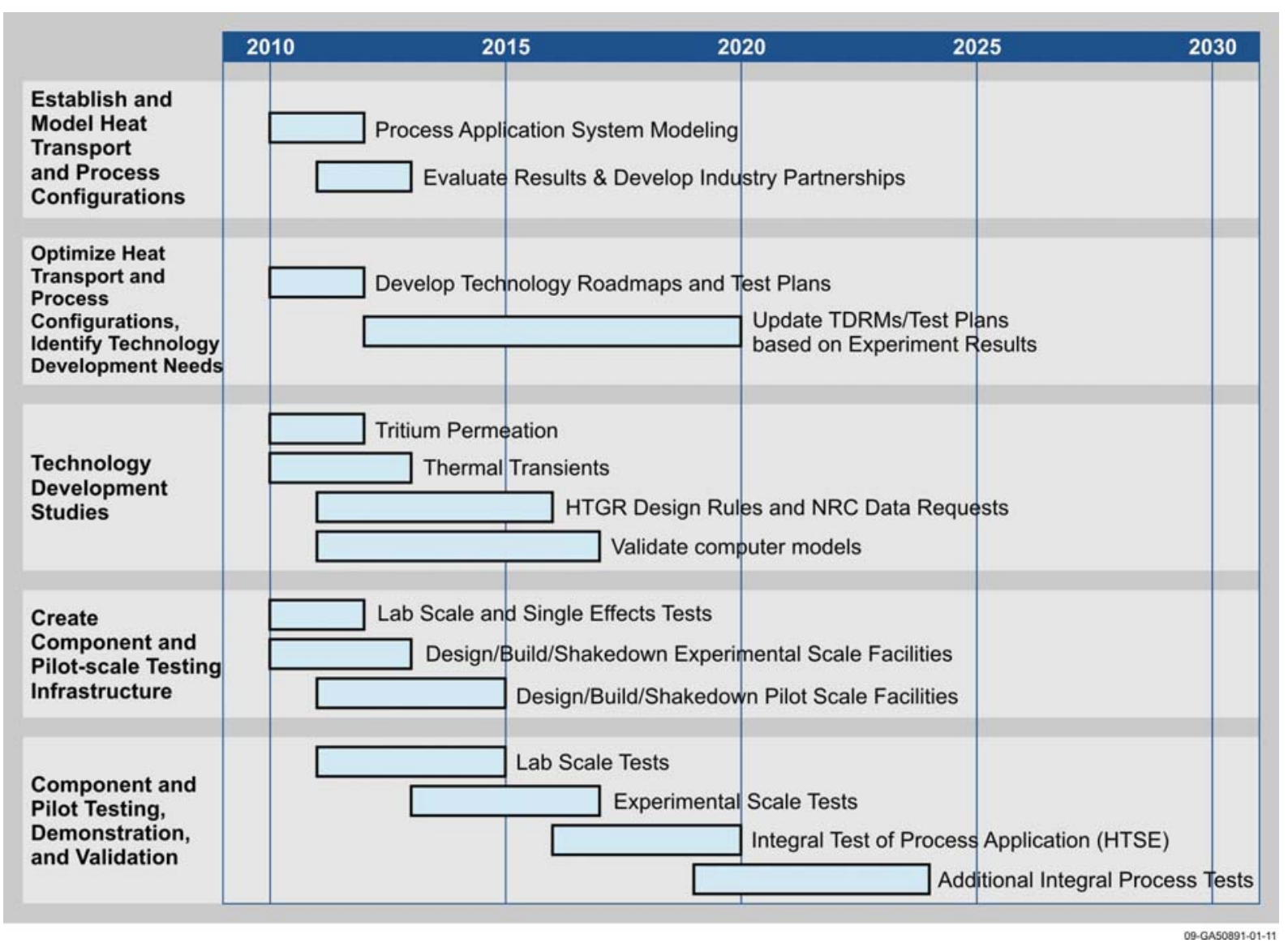

Figure 24. Schedule of heat transport activities. 


\section{HYDROGEN PRODUCTION}

Essentially carbon-free production of hydrogen can potentially play a key role in decreasing future petroleum imports, relieving the pressure on U.S. natural gas supplies and reducing emissions from transportation fuels. Beyond the need for process heat, hydrogen is a vital feedstock in the production of ammonia, upgrading of low-grade petroleum, and the production of synthetic transportation fuels, all potential end users for HTGR energy.

\subsection{Background and Objectives}

The Nuclear Hydrogen Initiative (NHI) in DOE-NE began in FY2004 to explore and develop methods for using the heat and/or electricity of high temperature reactors for the production of hydrogen from water. The specific objective of the NHI program was to support the national objectives of emission free, domestically based hydrogen, the NHI will develop efficient, large-scale hydrogen production methods suitable for use with advanced nuclear reactors. Based on these objectives, two research priorities were established: (1) to develop thermochemical and high-temperature electrolytic hydrogen production processes that match the thermal output characteristics of the NGNP to achieve economically competitive hydrogen production by 2017 and (2) to develop advanced or alternative processes to the baseline cycles to assess the potential for higher efficiency or lower cost options for NGNP by 2017.

This interest followed an earlier period of research in nuclear hydrogen production in the early 1980s during which the fundamental thermo-chemical processes were investigated by General Atomics (GA) in San Diego, the Europeans (primarily at the Joint Research Center in Ispra, Italy) and the Japanese, primarily at the Japan Atomic Energy Research Agency (JAERI). The start of the NHI followed closely a three-year Nuclear Energy Research Initiative (NERI) project which began in 1999 and involved researchers at GA, Sandia National Laboratories (SNL) and the University of Kentucky. NERI investigated 115 potential thermo-chemical hydrogen production processes against criteria such as the number of chemical reactions needed by the process, whether the process requires the handling of solids, the maximum temperatures required, the corrosive nature of the intermediate compounds and the efficiency of the overall process.

At the conclusion of the GA-UK NERI study, the researchers ranked the sulfur iodine process as the method most promising and potentially most efficient, which was supported by continuing experiments that were conducted at JAERI at Oarai on the sulfur-iodine process. The Japanese experiments reached a significant milestone in 2004, when a laboratory-scale experiment measuring about $2 \mathrm{~m}$ wide, $3.5 \mathrm{~m}$ long and $3 \mathrm{~m}$ high and using laboratory glassware succeeded in producing an average of 35 normal liters of hydrogen gas per hour for approximately 170 hours. The primary difficulties in the JAERI experiments were corrosion in the sulfuric acid decomposition section and incomplete separations of sulfuric acid, hydroiodic acid, and liquid iodine in the Bunsen reaction.

One of the initial decisions in organizing the NHI was to develop processes that were completely free of carbon, in order to avoid any need for ultimate sequestration of the $\mathrm{CO}_{2}$. Therefore, no experiments were performed on nuclear-assisted steam methane reforming under the NHI, despite the earlier recommendations of an Electric Power Research Institute (EPRI) study in 2003.

INL researchers submitted a NERI proposal in 2002 for the development of high-temperature electrolysis as an alternate method for hydrogen production. Over the next eight years, a series of tests starting at very small scale and proceeding to a large integrated demonstration were conducted to demonstrate hydrogen production from high temperature electrolysis. INL contracted with Ceramatec of Salt Lake City to produce button cells and short stacks and shortly thereafter reported the initial successful production of hydrogen at commercially relevant temperatures and current densities. The INL High Temperature Electrolysis project and Cermatec conducted button-cell experiments and an early sixcell stack that produced an average of 28 normal liters (NL) of hydrogen per hour for 1,100 hours. Using a slightly larger ten-cell stack, a test stand designed specifically for electrolytic testing, INL achieved a 
hydrogen production rate of 60 to $90 \mathrm{NL} / \mathrm{hr}$. Using a 25-cell stack, a production rate greater than 100 $\mathrm{NL} / \mathrm{hr}$ was sustained for more than 1,000 hours. Ceramatec also tested a half-module consisting of two 60-cell stacks in a configuration planned for the High Temperature Electrolysis (HTE) Integrated Laboratory Scale (ILS) experiment (see Figure 25). The half-module experiment ran for 2,040 hours, initially producing 1,200 NL/hr and averaging about $900 \mathrm{NL} / \mathrm{hr}$. For more than 800 hours of the test, the half-module operated in the co-electrolysis mode, converting a mixture of $\mathrm{CO}_{2}$ and steam into synthesis gas $\left(\mathrm{CO}+2 \mathrm{H}_{2}\right)$. During the test, the half-module produced sufficient syngas for about 110 gallons of diesel fuel, if a Fischer-Tropsch catalyst had been used. The HTE ILS tested three modules, which incorporated 720 cells, producing a maximum of 5,650 NL/hr after a total of 1,080 hours of operation. However, degradation in the cell production was observed. Based on an experts' workshop, changes in both configurations and materials sets were made. Some of these suggestions were incorporated in a subsequent test of a ten-cell stack, which was tested for 2,500 hours during May-September, 2009. This ten-cell stack had a degradation rate of $8.2 \%$ per 1,000 hours, much better than the best previous test's degradation of $21 \%$ per 1,000 hours.
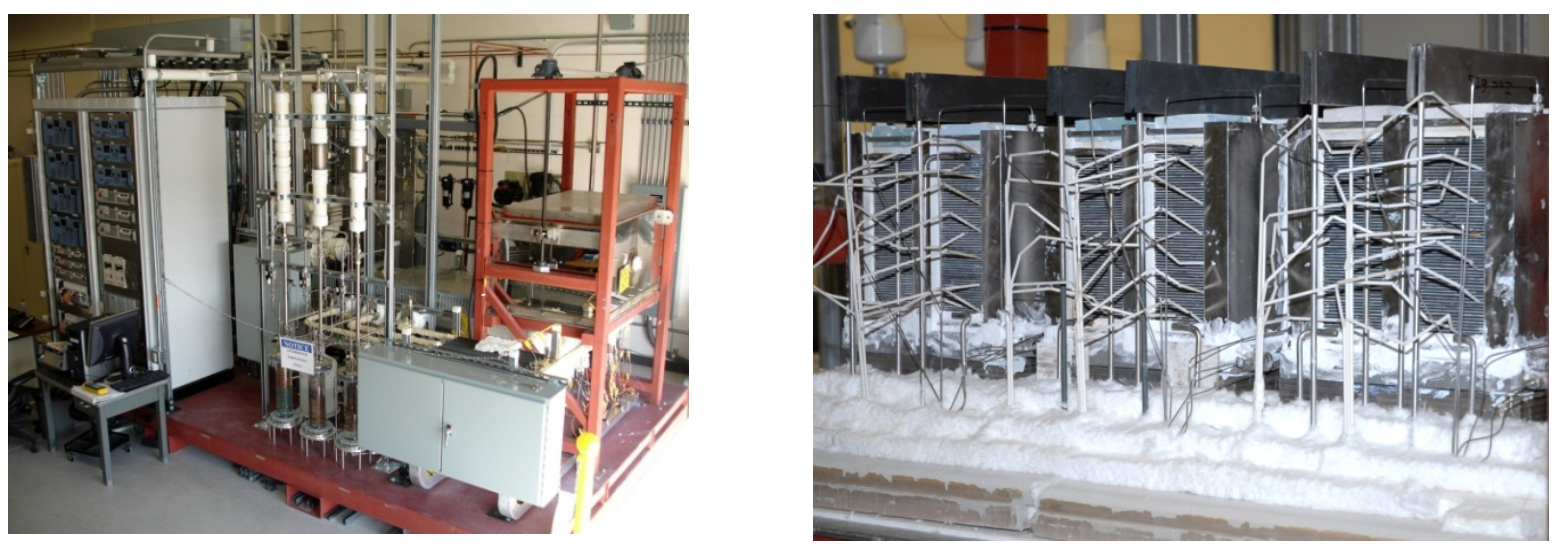

Figure 25. HTE integrated lab-scale experiment (left) and three electrolytic modules (right).

In parallel with the experimental program, the HTE project performed CFD and flowsheet analyses to model both planned experiments and possible commercial hydrogen production plants. The models were compared with the results of experiments for validation and insight into cell and stack performance. Based on this R\&D, high temperature electrolysis (HTE) was demonstrated to be an efficient and modular method for producing hydrogen using nuclear energy.

The development of the sulfur-iodine (S-I) process under the NHI also progressed from bench scale experiments to the construction of an ILS experiment. The S-I ILS experiment was a collaboration between GA, which built the hydroiodic acid decomposition section, SNL, which built the sulfuric acid decomposition section, and the Commissariat à l'Énergie Atomique (CEA) in France, which built the Bunsen reaction section, in which the acids are produced from I2, SO2 and water. The three sections were tested together at the General Atomics facilities in San Diego.

Because of difficulties in obtaining components of the required sizes, the three sections were not scaled for the same hydrogen production rate. The SNL sulfuric acid decomposition section operated several times at 100-300 NL/hr rates, while the redesigned GA hydroiodic acid decomposition section operated at $10-75 \mathrm{NL} / \mathrm{hr}$ rates.

\subsection{Future Plans}

HTE was recently selected by DOE as the hydrogen generation technology of choice after it was recommended by an independent review team ${ }^{18}$ for use with the planned NGNP based on its maturity and ease of integration with nuclear systems. The review team also recommended that HTE R\&D "(1) refine 
the understanding of cell/stack degradation modes and mechanisms, and (2) demonstrate pressurized cell/stack operation at a laboratory scale." The report also recommended evaluation of other alternative cell and stack designs. The path forward follows these recommendations and is organized into five major issues that must be addressed in the next 10-years and the strategy for resolving each issue.

\subsubsection{Improvements in Cell Performance}

The performance of solid-oxide cells in the electrolytic mode must improve before this technology will be ready for commercial application. The strategy will be to focus on development of cells and stacks optimized for the electrolysis application. Based upon previous testing experience, the emphasis will shift from electrolyte-supported cell designs to advanced electrode- or metal-substrate-supported cell designs. The key variables in the cell designs will include cell architecture and the composition and fabrication methodology for all cell layers. In this context, an expansion of industrial collaboration is planned with a range of cell manufacturers and research institutions.

\subsubsection{Larger Format Cells}

Larger cells will be required in the large-scale nuclear production of hydrogen. The manufacture of larger format cells (up to $1 \mathrm{~m} \times 1 \mathrm{~m}$ ) will require innovative cell designs and fabrication methods. Electrode-supported and porous-metal-supported cells show great potential for large-format designs. The current state of the art for large-format cells is about $25 \times 25 \mathrm{~cm}$, with electrode-supported cells. Several large companies and research centers are developing porous-metal-supported cell designs for the fuel-cell application, with the electrode and electrolyte layers deposited by thermal spray techniques. These cells can achieve very large sizes, up to $1 \times 1 \mathrm{~m}$. Work is planned with all potential cell providers in exploring the development of large-format cells for electrolysis, based on their respective technologies.

\subsubsection{Pressurized Operation}

Commercial HTE units will have to operate at elevated pressure in order to reduce manifold sizes and pumping power for insertion of the hydrogen into a pipeline or fuel synthesis/refining plant. Analyses and a design for a pressurized test stand will be developed. Elevated-pressure tests of a multi-cell stack will be conducted - probably in 2011 - after the previous two issues are successfully addressed. This work is required to validate the technology at the component level in a relevant operating environment.

\subsubsection{Scientific Understanding of Electrolytic Operation}

A deeper understanding of the implications of various cell and stack designs on details of cell, stack, and overall system performance is needed to complement the basic CFD and system analysis capability. These insights will be gained using advanced post-test examination methods for evaluating degradation mechanisms. The combined physical and numerical analysis will lead to optimized multi-cell and multi-stack manifolding and electrical interconnections.

\subsubsection{Needs for Engineering Data for HTGR Design}

HTE analyses and experiments must be coordinated with the needs for HTE-specific design data by the HTGR engineering teams. These design data needs for HTE have been identified and are being incorporated into a database. The specific parameters and their identified uncertainties will guide the design and operation of HTE experiments and their associated analyses. These data needs may need modification in the future to address the results of the ongoing engineering designs.

\subsection{Plans for Hydrogen Production Demonstration by NGNP}

Beyond the near term activities described above, in the longer term, plans exist to develop hydrogen production capability for the NGNP. The approach to the development of HTE has been and will continue to be an emphasis on modularity and progressively larger sizes and operating durations. The next step in that development, to occur in 2013 - 2015, will be the operation of a pressurized high temperature 
electrolyser, first as a ten-cell stack and progressing to a $200 \mathrm{kWe}$ multi-module experiment operating at 3 to $5 \mathrm{MPa}$.

The first HTE unit to be driven by the NGNP, in about 2019, will be the Engineering Demo, with size of 1 to $5 \mathrm{MWe}$. The Demo will operate at 3-5 $\mathrm{MPa}$ and $800^{\circ} \mathrm{C}$ will heat recuperation to allow lower steam input temperatures. The Demo units will have progressively more cells and multiple stacks, concluding with a unit having two stacks of 1,250 cells each, a total power of $5 \mathrm{MWe}$, a terminal voltage of 1,600 VDC and a working pressure of $5 \mathrm{MPa}$. The planned commercial unit would have four stacks and a module power of $9.6 \mathrm{MWe}$. The commercial plant would contain 32 of the $9.6 \mathrm{MWe}$ units for a total output of $160 \mathrm{t}$ of hydrogen per day, The commercial units would thus be truck-transportable and capable of stack repair while the other units remain operating.

The schedule for the hydrogen production research is shown in Figure 26.

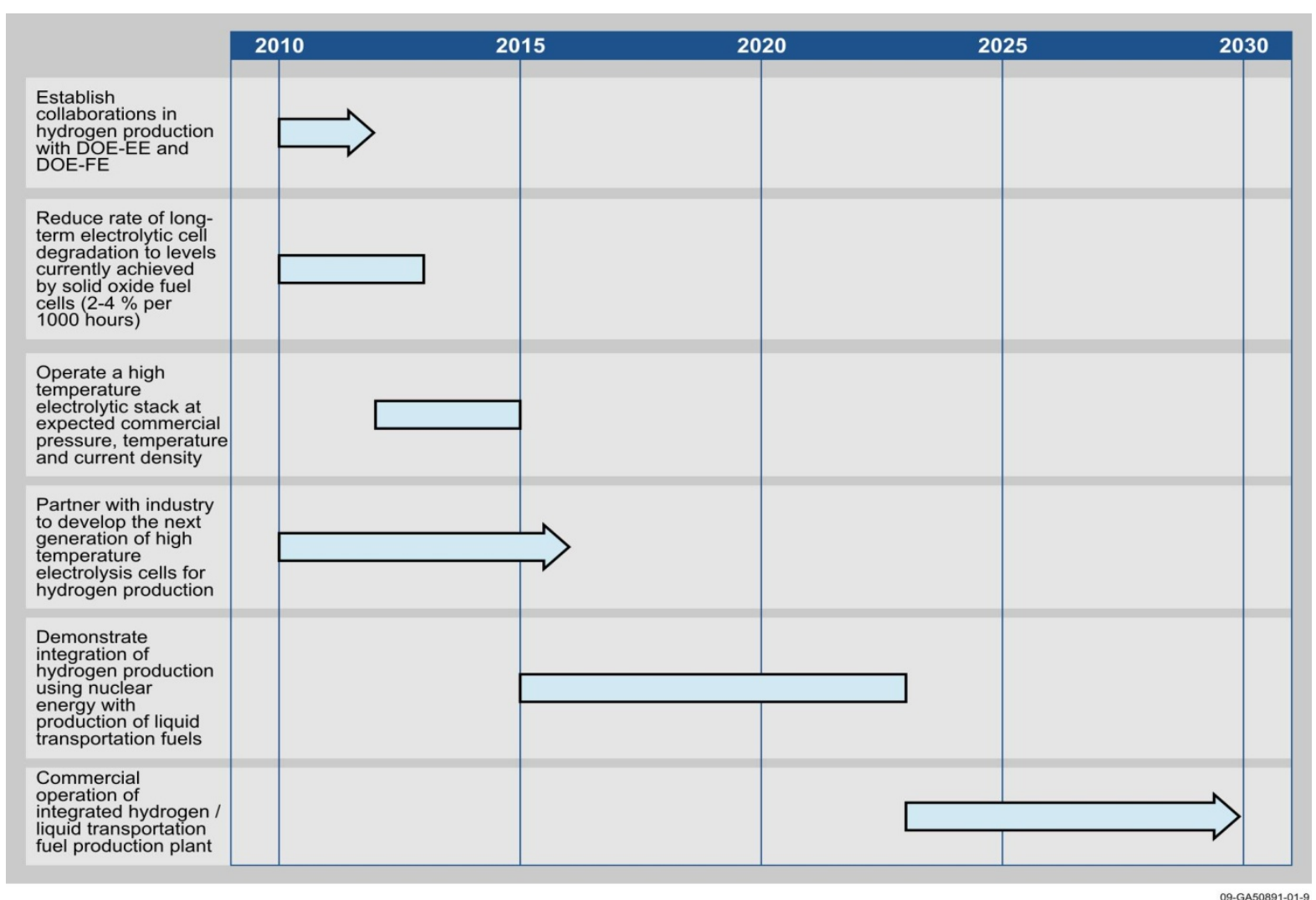

Figure 26. Hydrogen production research schedule. 


\section{INTERNATIONAL INTEREST IN HIGH TEMPERATURE GAS REACTORS}

Following the development of the Generation IV roadmap, the following countries expressed interest in pursuing aspects of HTGR technology with the United States as part of the Generation IV gas reactor project arrangement: China, Japan, Korea, EU, France, South Africa, England and Canada. As time has evolved, interests in the different countries have changed as national priorities have shifted. The following summarizes the current status/interest of HTGR technology worldwide.

\subsection{China}

China has an active gas reactor program with a $10 \mathrm{MWt}$ pebble bed, HTR-10, at INET north of Beijing, operated by Tsinghua University. They are currently planning for deployment of a number of high temperature gas reactors to produce electricity under their HTR-PM project. The design incorporates two $250 \mathrm{MWt}$ pebble bed reactors based on the German HTR-Modul design feeding a 200 MWe steam turbine-generator. The site for the first HTR-PM has been cleared and prepared for pouring of concrete, which is anticipated soon. They have only recently gained approval to join the Generation IV project arrangement and based on recent discussions with the Chinese at the INL we anticipate collaboration in that venue in the future.

\subsection{Japan}

The 30 MWt High Temperature Test Reactor (HTTR) is one of two currently operating HTGR test reactors. It has been performing a variety of tests and operational transients to support international efforts including the NGNP project. Japan has produced a conceptual design of a power reactor, GTHTR300, a $600 \mathrm{MWt} / 280 \mathrm{MWe}$ prismatic HTGR designed to produce hydrogen, steam and electricity. Nationally, Japan is focusing most of its R\&D advanced reactor resources on fast reactors. Japanese participation in the Generation IV high temperature gas reactor project arrangement is at a minimal level in light of current nuclear energy R\&D budget priorities.

\subsection{France}

The French were initially very active in high temperature gas cooled reactor technology based on the ANTARES prismatic reactor design (a $600 \mathrm{MWt}$ prismatic) and still lead the international activities under the Generation IV project arrangement. They have also supplied fuel for the AGR-2 irradiation currently

underway at INL. However, recent changes in priorities in France have focused all efforts on sodium fast reactor technology leading to the design and construction of a new fast reactor. They have requested that all collaborative tasks under the Generation IV gas reactor project arrangement be put in an indefinite status pending additional clarification from their government.

\subsection{European Union (EU)}

The Europeans have contributed significantly to worldwide gas reactor technology development under the RAFAEL framework. That framework recently ended and a new proposal for follow-on R\&D work is currently under review by the EU ministry in Brussels. The Europeans have recently established a project called EUROPAIRS to understand end user needs for process heat, electricity, hot gas and hydrogen, similar to that done in the U.S. by the NGNP project. The U.S. participates in the EUROPAIRS meetings. They are about 2 years behind the U.S. effort. 


\subsection{IAEA}

The IAEA has conducted a Coordinated Research Project (CRP) on HTGR fuel technology, with documentation of results in the form of a TECDOC expected to be completed in 2010. A follow-on CRP is under discussion.

\subsection{Korea}

Initially, Korea had a very aggressive program to deploy gas cooled reactors. However, over the past few years, the program has been scaled back to one of technology development with a decision on deployment delayed until the technology is more developed. They have an ongoing technology development program with emphasis on development of coated particle fuel technology. They have been active participants in the Generation IV project arrangement.

\subsection{South Africa}

South Africa had a large and very vigorous reactor development and deployment project as part of the Pebble Bed Modular Reactor (PBMR) project, with over 800 personnel contributing to the project. They have also supplied fuel for the AGR-2 irradiation currently underway at INL. Significant hydraulic testing and fuel fabrication facilities were developed as part of the PBMR project. Financial troubles in the country have changed the priorities of the South African government with only a skeletal team of about 25 individuals remaining in the project.

\subsection{Russia}

The U.S. (NNSA) and Russia have been co-funding the development of a variation of the Gas Turbine - Modular Helium Reactor (GT-MHR) for consumption of weapons plutonium and production of electricity. The FY2011 NNSA budget includes \$5 million for the GT-MHR as the U.S. contribution.

\subsection{India}

The Indians are working on a high temperature reactor that is different than the helium-cooled graphite moderated modular reactors under development in the rest of the world. The Indian design uses TRISO fuel particles, is cooled by lead and uses refractory alloys for key structural components. The effort is still at a very early stage of development.

\subsection{Canada and England}

Both countries expressed interest in HTGR technology but today are only observers in the Generation IV gas reactor project arrangement because of each countries focus on their existing reactor industry. England continues to contribute expertise through the EU membership in Generation IV.

\subsection{Results from Generation IV and Other Collaborative Umbrellas}

Much of the R\&D being performed for NGNP is being offered under the Generation IV International Forum multilateral collaboration auspices. NGNP R\&D staff are actively engaged in project management boards (the collaboration vehicle) in the areas of (a) fuel and fuel cycle, (b) materials (both metals and graphite), (c) computational methods, and (d) hydrogen. Under this multilateral framework, R\&D being done in Europe, Asia, and South Africa is available to DOE and the NGNP project, offsetting some of the needed technology development for NGNP and supplementing the near-term NGNP R\&D with longer term technology development for the VHTR. These countries also get access to the data and analyses being conducted for the DOE NGNP project. Detailed project plans are established annually (and in some cases biannually) to establish milestones, discuss/evaluate technical results, and track execution of the work. 
A bilaterial collaboration exists with HTTR in Japan (a similar bilateral collaboration is also planned for HTR-10 in China) to obtain unique operational data from an operating prismatic reactor. For example, testing has been conducted at HTTR to measure tritium permeation through the heat-transport equipment as a function of outlet temperature (between 800 and $950^{\circ} \mathrm{C}$ ). Operational and design data that is not currently available in the public domain are also part of the collaboration. These data are very valuable to both the reactor designer and the code analyst for $\mathrm{V} \& \mathrm{~V}$ purposes.

Examples of important data being obtained from the Generation IV collaboration include:

- Irradiation (in tests EU-1 and EU-1bis) and accident safety testing of German $\mathrm{UO}_{2}$ pebbles to better understand the margins associated with the fuel form from Europe

- Material properties of irradiated coated particle layers in the PYCASSO-I and -II irradiations in Europe using samples from Korea and Japan

- Graphite irradiation response data for new grades of graphite from the European graphite irradiation program

- New analysis methods for developing constitutive models for creep-fatigue behavior

- Creep characterization of Alloy 617 in helium

- Heavy section welding and stress relief practices for 200-mm-thick SA 508/533 pressure vessel steel. 


\section{REFERENCES}

1. Petti, David, Richard Hobbins, and James Kendall, 2008, Technical Program Plan for the Advanced Gas Reactor Fuel Development and Qualification Program, INL/EXT-05-00465, Revision 2, July 2008.

2. NGNP Fuel Qualification White Paper, INL/EXT-10-17686, July 2010

3. Mechanistic Source Term White Paper, INL/EXT-10-17997, July 2010

4. Barnes, C. M., and J. D. Hunn, 2010, "Fabrication and Comparison of Fuels for Advanced Gas Reactor Tests," 5th International Topical Meeting on High Temperature Reactor Technology (HTR2010), Prague, Czech Republic, October 18-20, 2010.

5. Grover, S. Blaine, D. A. Petti, and J. T. Maki, 2010, "Mission and Status of the First Two Next Generation Nuclear Plant Fuel Irradiation Experiments in the Advanced Test Reactor," Proceedings of the 18th International Conference on Nuclear Engineering, Xi an China, May 17-21, 2010.

6. Miller, G. K., J. T. Maki, D. L. Knudson, and D. A. Petti, 2004, "Current Capabilities of the Fuel Performance Modeling Code PARFUME," Proceedings of the Conference on High Temperature Reactors, HTR-2004, Beijing, China, September 22-24, 2004.

7. David Petti, Tim Abram, Ben Franklin, Richard Hobbins and Jim Kendall, "Assessment of Next Generation Nuclear Plant (NGNP) Fuel Acquisition Strategies," INL/EXT-07-12441, Rev 1, October 2007.

8. T. Burchell, R. Bratton, W. Windes, "NGNP Graphite Selection and Acquisition Strategy, ORNL/TM-2007/153, September 2007.

9. Windes, W., T. Burchell, R. Bratton, 2007, “Graphite Technology Development Plan,” PLN-2497, Rev 0, October 2007.

10. NGNP Materials White Paper, INL/EXT-09-17187, June 2010

11. "Next Generation Nuclear Plant Intermediate Heat Exchanger Materials Research and Development Plan," Idaho National Laboratory PLN-2804, April 2008.

12. Wright, R. N., and J. K. Wright, "Next Generation Nuclear Plant Reactor Pressure Vessel Materials Research and Development Plan," Idaho National Laboratory PLN-2803, Revision 1, 07/14/10.

13. R. E. Mizia, Next Generation Nuclear Plant Intermediate Heat Exchanger Acquisition Strategy, INL/EXT-08-14054, April 2008.

14. R. E. Mizia, Next Generation Nuclear Plant Reactor Pressure Vessel Acquisition Strategy, INL/EXT08-13951, April 2008.

15. Schultz, R., et al., "Next Generation Nuclear Plant Methods Technical Program Plan," Idaho National Laboratory, PLN-2498, Rev 1, 9/24/08.

16. General Atomics, MHTGR Nuclear Physics Benchmarks, DOE-HTGR-90406, San Diego, February 1994.

17. Reitsma, F., "The OECD/NEA/NSC PBMR 400 MW Coupled Neutronics Thermal Hydraulics Transient Benchmark: Transient Results", Proceedings of PHYSOR2010 Meeting, Pittsburgh, USA, May 9-14, 2010.

18. Varrin, R., et al., 2009, "NGNP Hydrogen Technology Down-Selection Results of the Independent Review Team (IRT) Evaluation,” R-6917-00-01, Revision 0, July 31, 2009. 